\title{
Shock in China 2018 (SIC-study): a cross-sectional survey
}

\author{
Longxiang Su${ }^{1 \#}$, Xudong Ma ${ }^{2 \#}$, Xi Rui ${ }^{1 \#}$, Huaiwu $\mathrm{He}^{1}$, Ye Wang ${ }^{3}$, Guangliang Shan ${ }^{3}$, Yan $\mathrm{Kang}^{4}$, \\ You Shang ${ }^{5}$, Ruiqiang Zheng ${ }^{6}$, Shusheng Li $^{7}$, Qingyuan Zhan ${ }^{8}$, Renyu Ding ${ }^{9}$, Yongjie Yin ${ }^{10}$, Li Jiang ${ }^{11}$, \\ Lina Zhang ${ }^{12}$, Qinggang Ge ${ }^{13}$, Liu Zhang ${ }^{14}$, Junyu Lu ${ }^{15}$, Linjun Wan ${ }^{16}$, Jing Yan ${ }^{17}$, Dawei Liu ${ }^{1}$, Yun Long ${ }^{1}$, \\ Xiangdong Guan ${ }^{18}$, Dechang Chen ${ }^{19}$, Xiang Zhou ${ }^{1}$, Shuyang Zhang ${ }^{20}$; on behalf of SIC study of China \\ National Critical Care Quality Control Center Group
}

${ }^{1}$ Department of Critical Care Medicine, State Key Laboratory of Complex Severe and Rare Diseases, Peking Union Medical College Hospital, Peking Union Medical College \& Chinese Academy of Medical Sciences, Beijing, China; ${ }^{2}$ Department of Medical Administration, National Health Commission of the People's Republic of China, Beijing, China; ${ }^{3}$ Department of Epidemiology and Biostatistics, Institute of Basic Medicine Sciences, Peking Union Medical College \& Chinese Academy of Medical Sciences, Beijing, China; ${ }^{4}$ Department of Critical Care Medicine, West China Hospital of Sichuan University, Chengdu, China; ${ }^{5}$ Department of Critical Care Medicine, Union Hospital, Tongji Medical College, Huazhong University of Science and Technology, Wuhan, China; ${ }^{6}$ Department of Critical Care Medicine, Northern Jiangsu People's Hospital, Yangzhou, China; ${ }^{7}$ Department of Critical Care Medicine, Tongji Hospital affiliated to Tongji Medical College Huazhong University of Science and Technology, Wuhan, China; ${ }^{8}$ Department of Respiratory and Critical Care Medicine, China-Japan Friendship Hospital, Beijing, China; ${ }^{9}$ Department of Critical Care Medicine, The First Hospital of China Medical University, Shenyang, China; ${ }^{10}$ Department of Emergency and Critical Care Medicine, The Second Hospital of Jilin University, Changchun, China; ${ }^{11}$ Department of Critical Care Medicine, Xuanwu Hospital Capital Medical University, Beijing, China; ${ }^{12}$ Department of Critical Care Medicine, Xiangya Hospital, Changsha, China; ${ }^{13}$ Department of Critical Care Medicine, Zhejiang Hospital, Hangzhou, China; ${ }^{14}$ Department of Critical Care Medicine, Peking University Third Hospital, Beijing, China; ${ }^{15}$ Department of Critical Care Medicine, Peking University People's Hospital, Beijing, China; ${ }^{16}$ Department of Critical Care Medicine, Guangxi Medical University Affiliated Hospital, Nanning, China; ${ }^{17}$ Department of Critical Care Medicine, Zhejiang Medical University Affiliated Hospital, Hangzhou, China; ${ }^{18}$ Department of Critical Care Medicine, the First Affiliated Hospital of Sun Yat-sen University, Guangzhou, China; ${ }^{19}$ Department of Critical Care Medicine, Ruijin Hospital affiliated to Medical College of Shanghai Jiaotong University, Shanghai, China; ${ }^{20}$ Department of Cardiology, Peking Union Medical College Hospital, Peking Union Medical College \& Chinese Academy of Medical Sciences, Beijing, China

Contributions: (I) Conception and design: X Zhou, D Liu, L Su; (II) Administrative support: X Zhou, S Zhang, X Ma; (III) Provision of study materials or patients: Y Long, Y Kang, Y Shang, R Zheng, S Li, Q Zhan, R Ding, Y Yin, L Jiang, L Zhang, Q Ge, L Zhang, J Lu, L Wan, J Yan, X Guan, D Chen; (IV) Collection and assembly of data: X Rui, H He; (V) Data analysis and interpretation: Y Wang, G Shan; (VI) Manuscript writing: All authors; (VII) Final approval of manuscript: All authors.

"These authors contributed equally to this work.

Correspondence to: Xiang Zhou. Department of Critical Care Medicine, Peking Union Medical College Hospital, Peking Union Medical College and Chinese Academy of Medical Sciences, Beijing 100730, China. Email: zx_pumc@163.com; Shuyang Zhang. Department of Cardiology, Peking Union Medical College Hospital, Peking Union Medical College and Chinese Academy of Medical Sciences, Beijing 100730, China. Email: shuyangzhang103@nrdrs.org.

Background: Shock is a critical illness that seriously threatens the lives of patients. This study explains the epidemiology of shock, mortality of shock, and identify factors that related to hospital death.

Methods: This is a multi-centre cross-sectional survey, which included 1,064 tertiary hospitals in 31 provinces, municipalities, and autonomous regions across China mainland. Totally 289,428 patients who diagnosed with shock based on the ICD-10 abstracted from the Hospital Quality Monitoring System (HQMS) in 2018, a national database administrated by National Health Commission of the PRC.

Results: Patients diagnosed with shock were screened and classified according to the type of shock. Regression analysis was used to identify factors that related to death. A total of 79,668,156 medical records were included in HQMS in 2018, from which a total of 289,428 records with shock were identified. Hypovolemic shock occurred in 128,436 cases (44.38\%), septic shock occurred in 121,543 cases (41.99\%), cardiogenic shock occurred in 44,597 cases (15.41), and obstructive shock occurred in 3,168 cases (1.09\%). Of these, 8,147 cases $(2.81 \%)$ had mixed shock, which means had two or more types of shock. For all 
the shock cases, the top three frequent concomitant diseases recorded were circulatory system diseases (55.22\%), digestive system diseases (53.64\%), and respiratory system diseases $(53.31 \%)$. Of the four types of shock, cases with cardiogenic shock had the highest in-hospital mortality $(31.6 \%)$, followed by those with obstructive shock (25.2\%), septic shock (22.9\%), and hypovolemic shock (15.5\%). Interestingly, the combination of shock and malignant tumors is one of the major factors that related to hospital deaths.

Conclusions: Shock is a serious disease with a high fatality rate and huge clinical costs. According to this epidemiological survey of shock in China 2018, we should clarify the factors related to the hospital death in shock cases.

Keywords: Shock; Hospital Quality Monitoring System (HQMS); outcome; risk factor; epidemiology

Submitted Jan 20, 2021. Accepted for publication Apr 25, 2021.

doi: $10.21037 /$ atm-21-310

View this article at: https://dx.doi.org/10.21037/atm-21-310

\section{Introduction}

Shock is defined as a life-threatening circulatory failure due to reduced oxygen delivery and/or increased oxygen consumption or insufficient oxygen utilization of cells and tissues, resulting in high morbidity and mortality $(1,2)$. Shock is not only a disease but also a circulatory disorder syndrome whose pathophysiological process might be triggered by a variety of pathogenic factors leading to metabolic disorders. Knowing the epidemiological characteristics of shock patients can allow clinicians to deeply understand the disease process and prevent disease progression. A cohort study conducted in the emergency department of Danish University Hospital from 2010 to 2011 showed that hypovolemic shock (30.8\%) and septic shock (27.2\%) were the most common types of shock in 1,553 shock patients, followed by non-septic symptomatic shock (23.4\%) and cardiogenic shock (14.0\%), while obstructive shock (0.9\%) was relatively rare (3). A clinical trial involving more than 1,600 patients with unexplained shock showed that the proportion of septic shock was approximately $62 \%$; others included cardiogenic shock in $16 \%$ and hypovolemic shock in $16 \%$, while other types of distributed shock (such as neurogenic shock and anaphylactic shock) accounted for $4 \%$ and obstructive shock accounted for $2 \%$ (4). However, the current understanding of the incidence, etiology, and related prognosis of shock is limited. Most existing studies are single-center, have small samples based on specific patients (septic shock/cardiogenic shock) and are conducted in specific environments (ICU/emergency). These studies suggest limited value for understanding the etiology of the entire patient population. Therefore, clarifying the description and prognosis of shock-related diseases in the entire population can provide clinical decisions to address these potential shock patients. In this article, we used patient medical records from 31 provinces and cities in mainland China in 2018 to explains the epidemiology of shock, mortality of shock, and identify factors that related to hospital death. We present the following article in accordance with the STROBE reporting checklist (available at https://dx.doi.org/10.21037/atm-21-310).

\section{Methods}

\section{Study design}

This cross-sectional analysis was based on data abstracted from Hospital Quality Monitoring System (HQMS) in China, 2018. The system included 31 provinces, municipalities, and autonomous regions in China. In each region, all the three-level hospitals in the region's capital city and local hospitals from a smaller city or rural county were enrolled but did not include private hospitals or military hospitals.

\section{Participants}

Data were collected between January 1, 2018, and December 31, 2018. In order to avoid potential sources of bias, the study included all the tertiary hospital in China mainland. In China, hospitals are graded according to a 3-tier system that recognizes a hospital's ability to provide medical care and medical education and conduct medical research. Accordingly, hospitals are graded into primary, secondary or tertiary institutions. Tertiary hospitals are comprehensive or general hospitals at the city, provincial or 
national level with a bed capacity exceeding 500 . They are responsible for providing specialist health services and play a larger role in medical education and scientific research. They serve as medical hubs providing care to multiple regions. A total of 79,668,156 patients medical records from 1,064 tertiary hospitals (urban $79.21 \%$ vs. rural 20.79\%) were included in this study.

\section{Shock definition and classification}

According to the characteristics of hemodynamics, shock can be divided into the following four categories: hypovolemic shock (from internal or external fluid loss), cardiogenic shock (e.g., acute myocardial infarction, endstage cardiomyopathy, advanced valvular heart disease, myocarditis, or cardiac arrhythmias), obstructive shock (e.g., pulmonary embolism, cardiac tamponade, or tension pneumothorax), or distributive shock (e.g., septic shock, neurogenic shock or anaphylactic shock) (5). The most important component due to distributive shock is septic shock, while neurogenic shock was rare $(\mathrm{n}=88)$, and other subtypes of distributed shock were not recorded in the ICD-10. Therefore, this study used the ICD-10 code "A41.953-954" to define septic shock for statistical analysis.

\section{Data sources and processing}

The data come from the HQMS, a national database administrated by National Health Commission the PRC, which includes the following information: (I) demographic characteristic : gender, age, occupation, ethnicity, etc.; (II) patients' medical record: admission department, admission diagnosis, main discharge diagnosis, other discharge diagnosis, surgical operation, days of hospitalization, cost of hospitalization, method of leaving hospital, etc.; (III) hospital information: province, medical institution level, etc. The screening of patients with shock was based on ICD-10 codes and China National Standard: GB/T 143962016 Classification and codes of diseases for discharge diagnosis, including "A41.953-954", defined as septic shock; "R57.000", defined as cardiogenic shock; "R57.101", defined as hypovolemic shock; and "R57.801", defined as obstructive shock. Logic errors were eventually selected for analysis.

\section{Outcome measures, exposure, and variables of interest}

The main outcome of the study was in-hospital death according to the medical record. In addition to gender, age, admission diagnosis, and comorbidities, other relevant variables are admission department (including internal medicine, surgery, emergency department, ICU), and region (divided into northeastern, northern, eastern, southern, central, southwestern, and northwestern China), GDP (three levels of GDP per capita in the province where the hospital is located in 2018), length of hospital stay, and hospitalization cost. It is emphasized that the patient's concomitant disease is judged according to the ICD-10 code of the discharge diagnosis other than shock on the first page of the medical record. Like the discharge diagnosis, it is divided into the following 15 categories, as shown in Table S1.

\section{Statistical analysis}

Continuous variables were described as the mean \pm standard deviation or median (quartile), and the frequency of variables (percentage) was used for classification variables. The missing data was defined as default value. The diagnosis rates of various comorbidities in shock patients were stratified by shock type and gender. In addition to calculations of the overall mortality rate of various shocks, the mortality rate of patients with other diseases was also calculated. The factors related to in-hospital death in shock patients were analyzed by multivariate logistic regression, and the OR values and $95 \%$ confidence intervals were calculated to find significant associations. The factors included in the analysis were gender, age, GDP, and comorbidities.

\section{Ethical statement}

The study was conducted in accordance with the Declaration of Helsinki (as revised in 2013). The study was authorized by the Office of Medical Administration of the National Health Commission of the PRC. The study was approved by the ethics committees of Peking Union Medical College Hospital (NO. S-K1297). All participating hospitals have approved by the ethics committees of the corresponding hospitals. All the individual consent for this retrospective analysis was waived.

\section{Results}

As shown in Figure 1, a total of 289,428 shock patients were included in this study. As shown in Table 1, the frequencies 


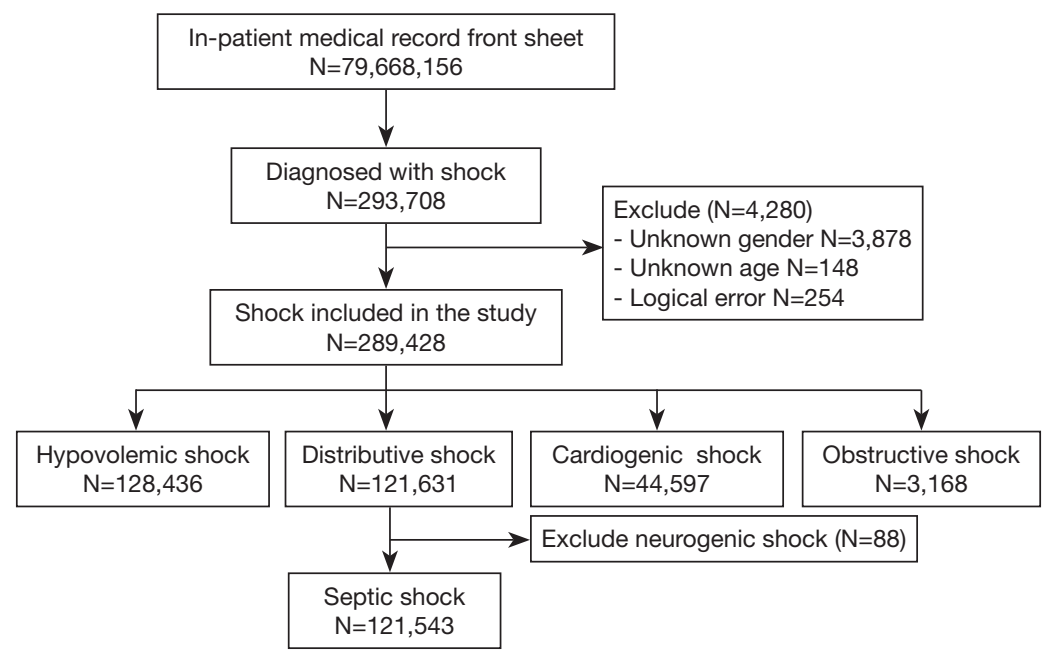

Figure 1 The flowchart of the patients involved in this study.

of shock according to the different causes of shock were as follows (the total ratio is greater than $100 \%$ due to mixed shock): 128,436 cases of hypovolemic shock, 121,543 cases of septic shock, 44,597 cases of cardiogenic shock, and 3,168 cases of obstructive shock. The majority of cases who suffered shock were men $(61.7 \%)$. The mean age of the cases was $59.5 \pm 20.7$ years. Among them, $62.2 \%, 56.5 \%$, and $54 \%$ of cases with cardiogenic shock, obstructive shock, and septic shock were elderly. The cases with hypovolemic shock were mainly young and middle-aged (64.9\%). Shock occurs less frequently in the total population among adolescents and children (4.4\%). The main source of these cases was from medical admission (44.6\%). According to ICD-10 codes recorded in HQMS, four shock-related frequency discharge diagnoses are classified: septic shock [symptoms, signs and abnormal clinical and laboratory findings, not elsewhere classified (SSACL, 22.5\%) > diseases of the respiratory system (DRS, 19.1\%) > diseases of the digestive system (DDS, 18.7\%)], cardiogenic shock [diseases of the circulatory system (DCS, 65.5\%) > SSACL (14.9\%)], hypovolemic shock [DDS $(31.2 \%)>$ injury, poisoning and certain other consequences of external causes (IPEC, 22.2\%) $>\operatorname{DRS}(17.7 \%)>\operatorname{DDS}(15.6 \%)]$, and obstructive shock [SSACL $(22.8 \%)>\operatorname{DRS}(17.7 \%)>\operatorname{DDS}(15.6 \%)>$ DCS (15.3\%)]. Among cases with obstructive shock according to GDP, the proportion of patients with middle levels of GDP was the highest (43.8\%), and the other three types of shock cases had the highest proportion of patients with high GDP levels (septic vs. cardiac vs. hypovolemic: $42 \%$ vs. $40.2 \%$ vs. $36.9 \%)$. The median length of hospital stay in septic shock was 11 days (4-20 days), that in cardiogenic shock was 6 days (1-13 days), that in hypovolemic shock was 9 days (4-18 days), and that in obstructive shock was 9 days (2-17 days). Septic shock accounts for the highest cost of hospitalization at $34,177.5(14,953-76,239)$ yuan, and the hospitalization costs of the remaining three types of shock are equivalent [obstructive $v s$. cardiogenic $v s$. hypovolemic: $25,094.2(10,797.5-55,144.8)$ vs. 23,682 (8399.5-55,924.2) vs. $21,775.9(10,248.6-53,038.9)$ yuan]. In terms of mortality, cardiogenic shock had the highest mortality rate (31.6\%), followed by obstructive shock (25.2\%), distributed shock (22.4\%), and hypovolemic shock (15.5\%).

In addition, we divided the cases into two groups as single shock and mixed shock (as shown in Table S2). Cases with mixed shock accounted for 8147/289,428 (2.81\%) of all shock patients. The description of mixed shock was shown as the Tables S3,S4. The majority of these population were older men $(62 \%)$ and those with internal medicine diseases (44.4\%), and the main discharge diagnoses were SSACL $(20.6 \%)>\operatorname{DCS}(16.9 \%)>\operatorname{DRS}(15.9 \%)>$ DDS $(14.8 \%)$. These people are mainly from the eastern $(21.1 \%)$ and southwestern regions (20.7\%) of China. Although the length of hospital stay is no longer than that of patients with a single type of shock [9 (3-20) vs. 9 (3-18) days], mixed shock incurs greater hospitalization costs $[45,744(17,431.6-$ $113,108.9)$ vs. $26,114(11,194.6-60,602)$ yuan] and has a higher mortality rate (37.7\% vs. $19.9 \%)$.

Statistics on complication are shown in Figure 2 and Tables S5-S8 for patients with different types of shock based on discharge diagnosis. Septic shock was mainly 
Table 1 Basic characteristics of patients by types of shock

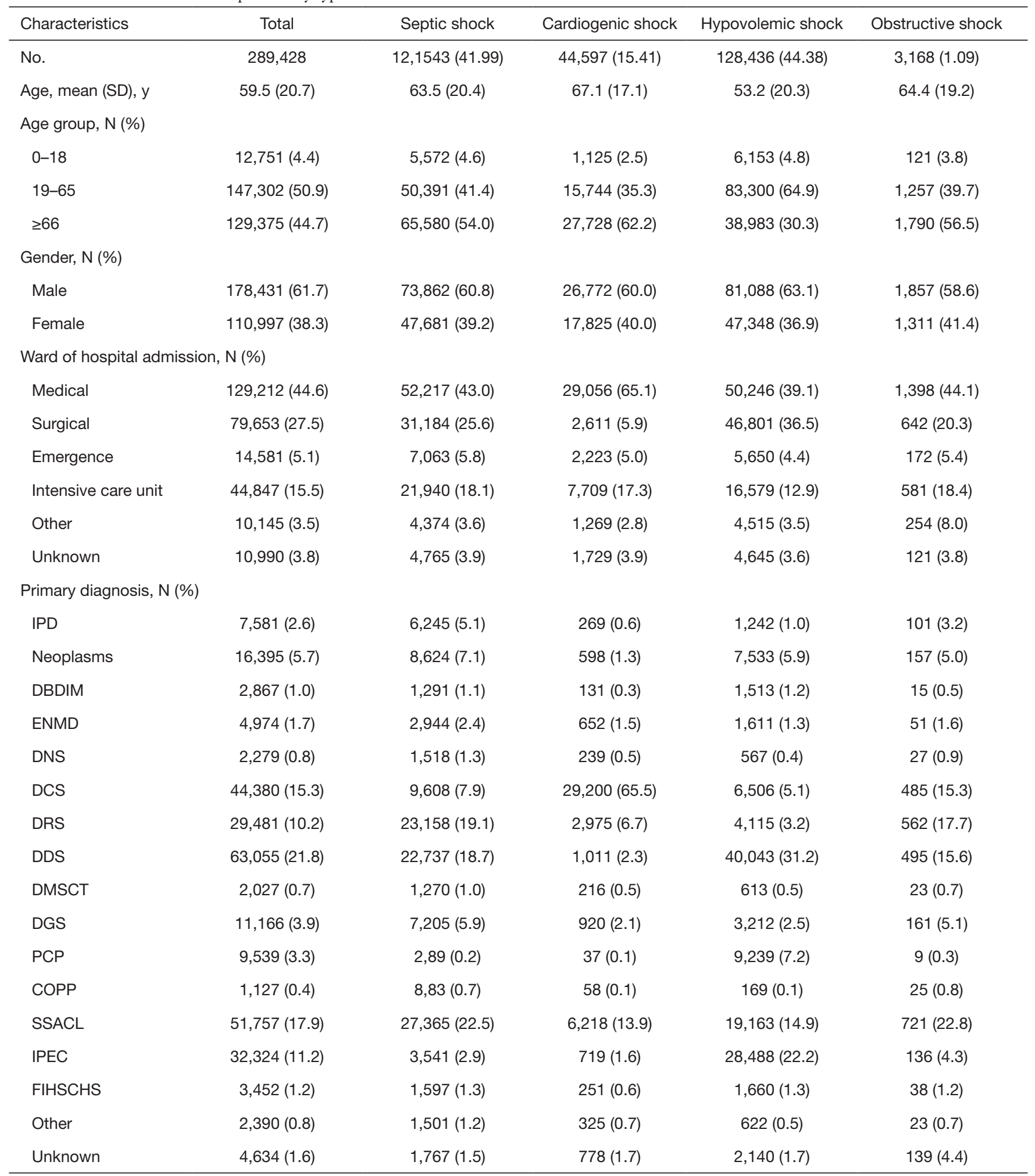

Table 1 (continued) 
Table 1 (continued)

\begin{tabular}{|c|c|c|c|c|c|}
\hline Characteristics & Total & Septic shock & Cardiogenic shock & Hypovolemic shock & Obstructive shock \\
\hline Northeast & $20,890(7.2)$ & 6,847 (5.6) & $3,868(8.7)$ & $9,904(7.7)$ & $812(25.6)$ \\
\hline North & $27,238(9.4)$ & $9,695(8.0)$ & $5,950(13.3)$ & $12,365(9.6)$ & $417(13.2)$ \\
\hline East & $70,226(24.3)$ & $31,453(25.9)$ & $10,408(23.3)$ & $29,466(23.0)$ & $650(20.5)$ \\
\hline Centre & $42,298(14.6)$ & $17,875(14.7)$ & $6,903(15.5)$ & $18,003(14.0)$ & $522(16.5)$ \\
\hline Northwest & $21,713(7.5)$ & $8,461(7.0)$ & $3,011(6.8)$ & $10,438(8.1)$ & $415(13.1)$ \\
\hline Southwest & $59,103(20.4)$ & $23,528(19.3)$ & 7,931 (17.8) & $29,157(22.7)$ & $209(6.6)$ \\
\hline \multicolumn{6}{|l|}{ GDP, N (\%) } \\
\hline Tertile 3 & $79,119(27.3)$ & $31,580(26.0)$ & $11,682(26.2)$ & $37,262(29.0)$ & $998(31.5)$ \\
\hline $\begin{array}{l}\text { Hospital stay, median } \\
\text { (IQR), days }\end{array}$ & 9 (3 to 18$)$ & 11 (4 to 20$)$ & $6(1$ to 13$)$ & 9 (4 to 18$)$ & $9(2$ to 17$)$ \\
\hline $\begin{array}{l}\text { Hospital cost, median } \\
(\text { IQR), RMB }\end{array}$ & $\begin{array}{c}26,496.1 \\
(11,302.2 \text { to } 61,741.5)\end{array}$ & $\begin{array}{c}34,177.5 \\
(14,953.0 \text { to } 76,239.0)\end{array}$ & $\begin{array}{c}23,682 \\
(8,399.5 \text { to } 55,924.2)\end{array}$ & $\begin{array}{c}21,775.9 \\
(10,248.6 \text { to } 53,038.9)\end{array}$ & $\begin{array}{c}25,094.2 \\
(10,797.5 \text { to } 55,144.8)\end{array}$ \\
\hline Mortality, N (\%) & $58,957(20.4)$ & $27,255(22.4)$ & $14,112(31.6)$ & $19,939(15.5)$ & 798 (25.2) \\
\hline
\end{tabular}

IPD, infectious and parasitic disease; DBDIM, diseases of the blood and blood-forming organs and certain disorders involving the immune mechanism; ENMD, endocrine, nutritional and metabolic diseases; DNS, diseases of the nervous system; DCS, diseases of the circulatory system; DRS, diseases of the respiratory system; DDS, diseases of the digestive system; DMSCT, diseases of the musculoskeletal system and connective tissue; DGS, diseases of the genitourinary system; PCP, pregnancy, childbirth and the puerperium; COPP, certain conditions originating in the perinatal period; SSACL, symptoms, signs and abnormal clinical and laboratory findings, not elsewhere classified; IPEC, injury, poisoning and certain other consequences of external causes; FIHSCHS, factors influencing health status and contact with health services.

complicated with by respiratory diseases $(70.86 \%)$, followed by endocrine $(62.76 \%)$, circulatory $(59.39 \%)$ and digestive (57.83\%) conditions. For cardiogenic shock, DCS (97.99\%) are predominantly diagnosed, followed by DRS (58.53\%) and endocrine system (56.3\%). For hypovolemic shock, the digestive system was the most frequency (57.34\%), followed by the circulatory system $(45.05 \%)$ and the endocrine system $(42.8 \%)$. For obstructive shock, the respiratory system is dominant $(66.86 \%)$, followed by the circulatory $(66.76 \%)$ and endocrine systems $(58.33 \%)$. The further classification of four shock-related frequency complication and shock severity were shown in the Tables S9-S13. In addition, we classified cases into those with single shock and those with mixed shock (as shown in Figure S1 and Tables S14,S15). Mixed shock can easily occur when the respiratory $(77.51 \%)$, circulatory $(73.97 \%)$, endocrine
(69.29\%) and digestive systems (63.23\%) are all involved.

For the shock cases with other diagnoses (as shown in Figure 3 and Tables S16-S19), case with malignant tumors had the highest mortality rate. The top three mortality rates for patients with complications were as follows: septic shock: neoplasms $(31.77 \%)>$ SSACL $(28.41 \%)>$ diseases of the nervous system (DNS, 28.38\%); cardiogenic shock: neoplasms $(45.68 \%)>$ diseases of the blood and blood-forming organs and certain disorders involving the immune mechanism (DBDIM, 38.03\%) > diseases of the genitourinary system (DGS, 36.78\%); hypovolemic shock: neoplasms $(28.57 \%)>$ DNS $(25.47 \%)>$ SSACL $(25.34 \%)$; and obstructive shock: PCP $(45.45 \%)>$ neoplasms $(33.33 \%)>$ SSACL $(30.72 \%)$. Shock is further divided into single shock and mixed shock (as shown in Figure S2 and Tables S20-S22). The top three frequencies for mortality in 

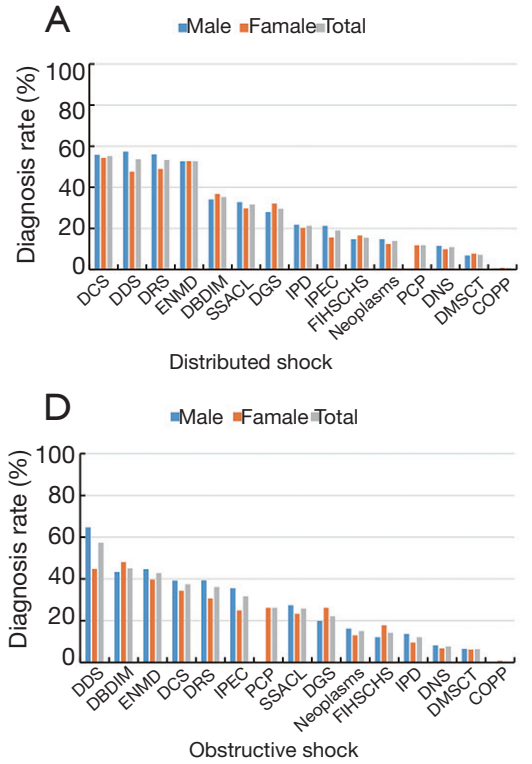

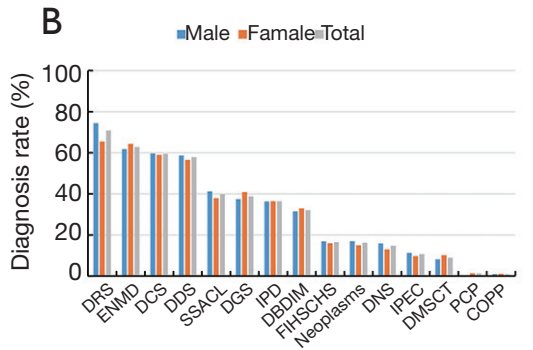

Hypovolemic shock

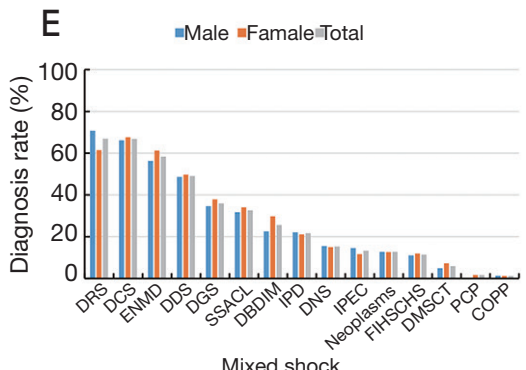

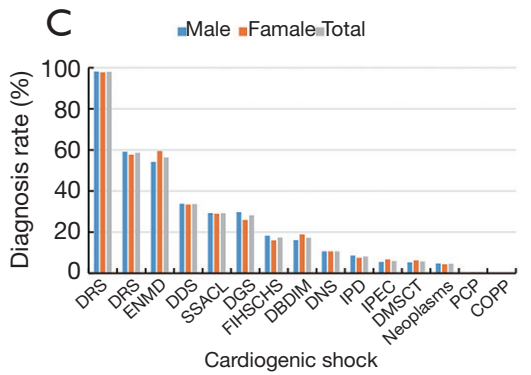

Cardiogenic shock

Figure 2 Diagnosis rate of various diagnoses in the shock patients. DCS, diseases of the circulatory system; DDS, diseases of the digestive system; DRS, diseases of the respiratory system; ENMD, endocrine, nutritional and metabolic diseases; DBDIM, diseases of the blood and blood-forming organs and certain disorders involving the immune mechanism; SSACL, symptoms, signs and abnormal clinical and laboratory; DGS, diseases of the genitourinary system; IPD, infectious and parasitic disease; IPEC, injury, poisoning and certain other consequences of external causes; FIHSCHS, Factors influencing health status and contact with health services; PCP, pregnancy, childbirth and the puerperium; DNS, diseases of the nervous system; DMSCT, diseases of the musculoskeletal system and connective tissue; DGS, diseases of the genitourinary system; COPP, certain conditions originating in the perinatal period.
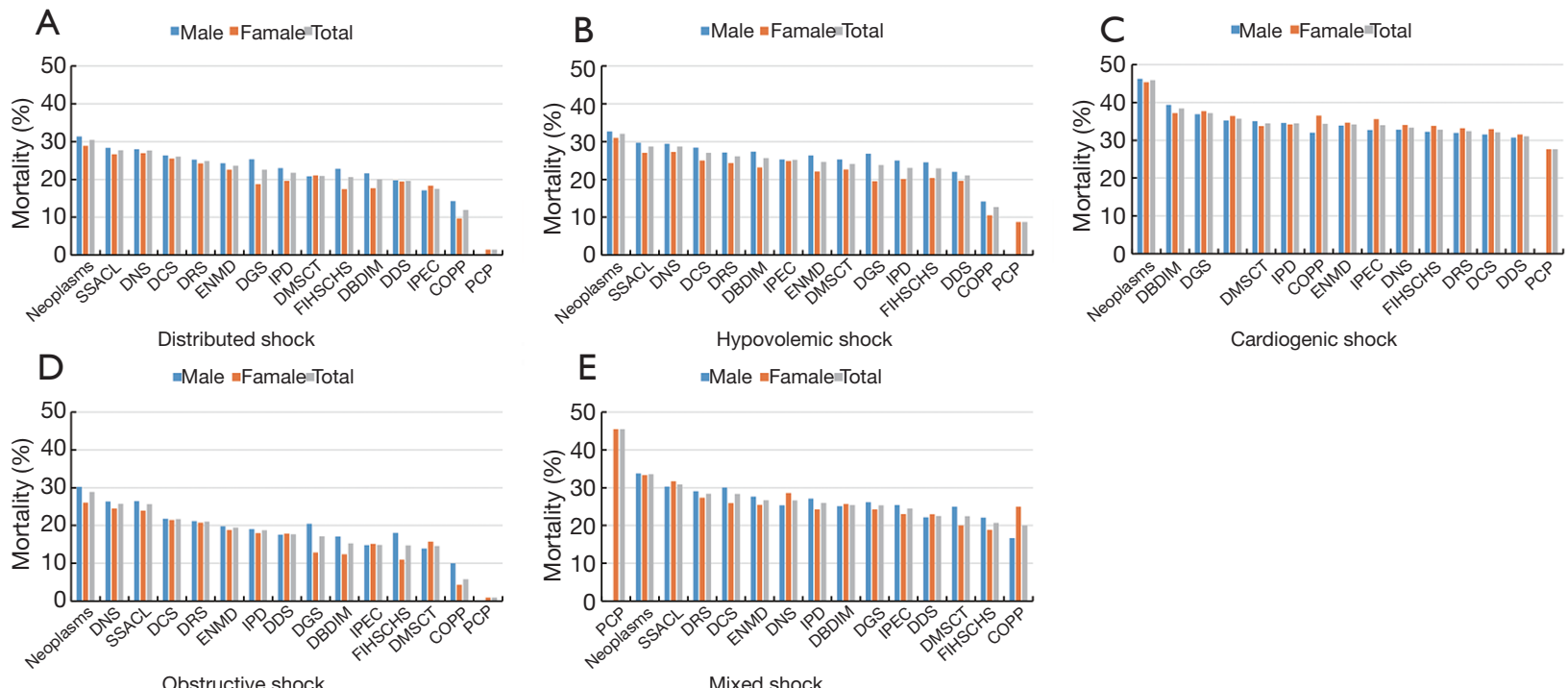

Figure 3 Diagnostic mortality in patients with shock. SSACL, symptoms, signs and abnormal clinical and laboratory; DNS, diseases of the nervous system; DCS, diseases of the circulatory system; DRS, diseases of the respiratory system; ENMD, endocrine, nutritional and metabolic diseases; DGS, diseases of the genitourinary system; IPD, infectious and parasitic disease; DMSCT, diseases of the musculoskeletal system and connective tissue; FIHSCHS, Factors influencing health status and contact with health services; DBDIM, diseases of the blood and blood-forming organs and certain disorders involving the immune mechanism; DDS, diseases of the digestive system; IPEC, injury, poisoning and certain other consequences of external causes; COPP, certain conditions originating in the perinatal period; PCP, pregnancy, childbirth and the puerperium. 
Table 2 Risk factors for hospital death in patients with different type of shock

\begin{tabular}{|c|c|c|c|c|c|c|c|c|c|c|c|c|c|c|c|}
\hline & \multicolumn{3}{|c|}{ Total } & \multicolumn{3}{|c|}{ Septic shock } & \multicolumn{3}{|c|}{ cardiogenic shock } & \multicolumn{3}{|c|}{ Hypovolemic shock } & \multicolumn{3}{|c|}{ obstructive shock } \\
\hline \multicolumn{16}{|c|}{ Age, y (vs. 0-10) } \\
\hline $0-20$ & 1.05 & $\begin{array}{c}0.94 \\
-1.17\end{array}$ & 0.4 & 1 & $\begin{array}{c}0.84 \\
-1.18\end{array}$ & 0.97 & 1.15 & $\begin{array}{c}0.87 \\
-1.51\end{array}$ & 0.34 & 1.29 & $\begin{array}{c}1.10 \\
-1.53\end{array}$ & 0.002 & 1.42 & $\begin{array}{c}0.41 \\
-4.86\end{array}$ & 0.58 \\
\hline $31-40$ & 1.17 & $\begin{array}{c}1.08 \\
-1.27\end{array}$ & $<0.001$ & 1.24 & $\begin{array}{c}1.10 \\
-1.41\end{array}$ & $<0.001$ & 0.81 & $\begin{array}{c}0.65 \\
-1.00\end{array}$ & 0.05 & 1.5 & $\begin{array}{l}1.31- \\
1.71\end{array}$ & $<0.001$ & 1.8 & $\begin{array}{c}0.77 \\
-4.20\end{array}$ & 0.18 \\
\hline $41-50$ & 1.2 & $\begin{array}{c}1.12 \\
-1.30\end{array}$ & $<0.001$ & 1.11 & $\begin{array}{c}0.99 \\
-1.24\end{array}$ & 0.06 & 0.88 & $\begin{array}{c}0.73 \\
-1.06\end{array}$ & 0.18 & 1.61 & $\begin{array}{c}1.42 \\
-1.83\end{array}$ & $<0.001$ & 2.13 & $\begin{array}{c}0.99 \\
-4.56\end{array}$ & 0.05 \\
\hline$>70$ & 2.01 & $\begin{array}{c}1.87 \\
-2.15\end{array}$ & $<0.001$ & 1.76 & $\begin{array}{c}1.59 \\
-1.94\end{array}$ & $<0.001$ & 1.51 & $\begin{array}{c}1.28 \\
-1.78\end{array}$ & $<0.001$ & 2.76 & $\begin{array}{c}2.44 \\
-3.13\end{array}$ & $<0.001$ & 2.75 & $\begin{array}{c}1.34 \\
-5.63\end{array}$ & 0.006 \\
\hline $\begin{array}{l}\text { Gender } \\
\text { (female vs. } \\
\text { male) }\end{array}$ & 0.91 & $\begin{array}{c}0.89 \\
-0.93\end{array}$ & $<0.001$ & 0.86 & $\begin{array}{c}0.83 \\
-0.88\end{array}$ & $<0.001$ & 1.01 & $\begin{array}{c}0.97 \\
-1.06\end{array}$ & 0.55 & 0.93 & $\begin{array}{c}0.90 \\
-0.96\end{array}$ & $<0.001$ & 0.92 & $\begin{array}{c}0.77 \\
-1.09\end{array}$ & 0.32 \\
\hline \multicolumn{16}{|c|}{ GDP (vs. tertile 1) } \\
\hline Tertile 2 & 0.94 & $\begin{array}{c}0.91 \\
-0.96\end{array}$ & $<0.001$ & 0.97 & $\begin{array}{c}0.94 \\
-1.00\end{array}$ & 0.05 & 0.79 & $\begin{array}{c}0.75 \\
-0.83\end{array}$ & $<0.001$ & 0.96 & $\begin{array}{c}0.92 \\
-0.99\end{array}$ & 0.02 & 1.3 & $\begin{array}{c}1.05 \\
-1.61\end{array}$ & 0.02 \\
\hline $\begin{array}{l}\text { DBDIM } \\
\text { (yes vs. no) }\end{array}$ & 0.98 & $\begin{array}{c}0.96 \\
-1.00\end{array}$ & 0.02 & 1.13 & $\begin{array}{c}1.10 \\
-1.17\end{array}$ & $<0.001$ & 1.24 & $\begin{array}{c}1.17 \\
-1.31\end{array}$ & $<0.001$ & 0.85 & $\begin{array}{c}0.82 \\
-0.88\end{array}$ & $<0.001$ & 0.96 & $\begin{array}{c}0.79 \\
-1.17\end{array}$ & 0.7 \\
\hline $\begin{array}{l}\text { ENMD } \\
\text { (yes vs. no) }\end{array}$ & 1.13 & $\begin{array}{c}1.11 \\
-1.16\end{array}$ & $<0.001$ & 1.12 & $\begin{array}{c}1.09 \\
-1.16\end{array}$ & $<0.001$ & 1.17 & $\begin{array}{c}1.12 \\
-1.22\end{array}$ & $<0.001$ & 1.1 & $\begin{array}{c}1.06 \\
-1.14\end{array}$ & $<0.001$ & 1.12 & $\begin{array}{c}0.93 \\
-1.34\end{array}$ & 0.23 \\
\hline $\begin{array}{l}\text { DNS } \\
\text { (yes vs. no) }\end{array}$ & 1.24 & $\begin{array}{l}1.21- \\
1.28\end{array}$ & $<0.001$ & 1.22 & $\begin{array}{c}1.17 \\
-1.26\end{array}$ & $<0.001$ & 1 & $\begin{array}{c}0.93 \\
-1.07\end{array}$ & 0.95 & 1.56 & $\begin{array}{c}1.48 \\
-1.64\end{array}$ & $<0.001$ & 0.96 & $\begin{array}{c}0.77 \\
-1.21\end{array}$ & 0.75 \\
\hline $\begin{array}{l}\text { DCS } \\
\text { (yes vs. no) }\end{array}$ & 1.63 & $\begin{array}{c}1.59 \\
-1.66\end{array}$ & $<0.001$ & 1.49 & $\begin{array}{c}1.44 \\
-1.54\end{array}$ & $<0.001$ & 1.14 & $\begin{array}{c}0.98 \\
-1.33\end{array}$ & 0.09 & 1.33 & $\begin{array}{c}1.28 \\
-1.37\end{array}$ & $<0.001$ & 1.41 & $\begin{array}{c}1.16 \\
-1.72\end{array}$ & $<0.001$ \\
\hline $\begin{array}{l}\text { DRS } \\
\text { (yes vs. no) }\end{array}$ & 1.21 & $\begin{array}{c}1.19 \\
-1.24\end{array}$ & $<0.001$ & 1.59 & $\begin{array}{c}1.53 \\
-1.65\end{array}$ & $<0.001$ & 0.9 & $\begin{array}{c}0.86 \\
-0.94\end{array}$ & $<0.001$ & 1.17 & $\begin{array}{c}1.13 \\
-1.21\end{array}$ & $<0.001$ & 1.43 & $\begin{array}{c}1.18 \\
-1.74\end{array}$ & $<0.001$ \\
\hline $\begin{array}{l}\text { DDS } \\
\text { (yes vs. no) }\end{array}$ & 0.76 & $\begin{array}{c}0.74 \\
-0.77\end{array}$ & $<0.001$ & 0.8 & $\begin{array}{c}0.78 \\
-0.83\end{array}$ & $<0.001$ & 0.82 & $\begin{array}{c}0.78 \\
-0.86\end{array}$ & $<0.001$ & 0.94 & $\begin{array}{c}0.91 \\
-0.98\end{array}$ & 0.002 & 0.79 & $\begin{array}{c}0.66 \\
-0.94\end{array}$ & 0.006 \\
\hline
\end{tabular}

Table 2 (continued) 
Table 2 (continued)

\begin{tabular}{|c|c|c|c|c|c|c|c|c|c|c|c|c|c|c|c|}
\hline & \multicolumn{3}{|c|}{ Total } & \multicolumn{3}{|c|}{ Septic shock } & \multicolumn{3}{|c|}{ cardiogenic shock } & \multicolumn{3}{|c|}{ Hypovolemic shock } & \multicolumn{3}{|c|}{ obstructive shock } \\
\hline \multicolumn{16}{|l|}{ Diagnosis } \\
\hline $\begin{array}{l}\text { DMSCT } \\
\text { (yes vs. no) }\end{array}$ & 0.89 & $\begin{array}{c}0.86 \\
-0.92\end{array}$ & $<0.001$ & 1.02 & $\begin{array}{c}0.97 \\
-1.07\end{array}$ & 0.47 & 1.02 & $\begin{array}{c}0.94 \\
-1.11\end{array}$ & 0.64 & 0.71 & $\begin{array}{c}0.66 \\
-0.76\end{array}$ & $<0.001$ & 0.87 & $\begin{array}{c}0.60 \\
-1.25\end{array}$ & 0.44 \\
\hline $\begin{array}{l}\text { PCP } \\
\text { (yes vs. no) }\end{array}$ & 0.13 & $\begin{array}{c}0.11 \\
-0.15\end{array}$ & $<0.001$ & 0.63 & $\begin{array}{c}0.47 \\
-0.84\end{array}$ & 0.002 & 1.02 & $\begin{array}{c}0.63 \\
-1.66\end{array}$ & 0.94 & 0.12 & $\begin{array}{c}0.10 \\
-0.14\end{array}$ & $<0.001$ & 5.33 & $\begin{array}{c}1.97 \\
-14.44\end{array}$ & 0.001 \\
\hline $\begin{array}{l}\text { COPP } \\
\text { (yes vs. no) }\end{array}$ & 1.13 & $\begin{array}{c}0.97 \\
-1.33\end{array}$ & 0.12 & 1.07 & $\begin{array}{c}0.88 \\
-1.30\end{array}$ & 0.52 & 1.39 & $\begin{array}{c}0.89 \\
-2.16\end{array}$ & 0.14 & 1.32 & $\begin{array}{c}0.89 \\
-1.97\end{array}$ & 0.17 & 1.56 & $\begin{array}{c}0.54 \\
-4.49\end{array}$ & 0.41 \\
\hline $\begin{array}{l}\text { FIHSCHS } \\
\text { (yes vs. no) }\end{array}$ & 0.93 & $\begin{array}{r}0.90 \\
-0.95\end{array}$ & $<0.001$ & 0.94 & $\begin{array}{r}0.90 \\
-0.97\end{array}$ & $<0.001$ & 0.97 & $\begin{array}{c}0.92 \\
-1.02\end{array}$ & 0.27 & 0.85 & $\begin{array}{c}0.81 \\
-0.89\end{array}$ & $<0.001$ & 0.67 & $\begin{array}{c}0.51 \\
-0.89\end{array}$ & 0.005 \\
\hline
\end{tabular}

IPD, infectious and parasitic disease; DBDIM, diseases of the blood and blood-forming organs and certain disorders involving the immune mechanism; ENMD, endocrine, nutritional and metabolic diseases; DNS, diseases of the nervous system; DCS, diseases of the circulatory system; DRS, diseases of the respiratory system; DDS, diseases of the digestive system; DMSCT, diseases of the musculoskeletal system and connective tissue; DGS, diseases of the genitourinary system; PCP, pregnancy, childbirth and the puerperium; COPP, certain conditions originating in the perinatal period; SSACL, symptoms, signs and abnormal clinical and laboratory findings, not elsewhere classified; IPEC, injury, poisoning and certain other consequences of external causes; FIHSCHS, factors influencing health status and contact with health services.

these two shocks were as follows: single shock: neoplasms $(29.98 \%)>$ SSACL $(27.09 \%)>$ DNS $(27.08 \%)$; mixed shock: neoplasms $(46.35 \%)>$ SSACL $(41.04 \%)>$ DGS (40.63\%).

Table 2 describes the factors related to in-hospital deaths in patients with shock. Compared with patients aged 0-10 years, the risk of death in patients over the age of 30 years increased significantly The OR for patients aged 30 years and above ranged from 1.17 to 2.01. Among patients with cardiogenic shock and obstructive shock, elderly patients $>70$ years of age are at a higher risk of death. The risk of septic shock among patients between 21-40 years of age and $>71$ years of age is higher, indicating that younger and older age are the main risk factors for septic shock death. For different causes, it is interesting that from an economic perspective, the risk of death in obstructive shock is lower in economically developed regions than in economically underdeveloped regions, while the remaining three types of shock pose a higher risk of death in economically developed regions than in economically underdeveloped regions.
Combining DDS $(\mathrm{OR}=0.8)$ and PCP $(\mathrm{OR}=0.64)$ have a lower mortality in septic shock. With neoplasms (OR $=2.04)>$ SSACL $(\mathrm{OR}=1.66)>\mathrm{DRS}(\mathrm{OR}=1.59)>\mathrm{DCS}$ $(\mathrm{OR}=1.49)>\mathrm{DNS}(\mathrm{OR}=1.22)>\operatorname{IPEC}(\mathrm{OR}=1.2)$ have a higher mortality rate. Regarding to cardiogenic shock, DDS (OR $=0.82)$, while neoplasms $(\mathrm{OR}=1.75)>$ certain conditions originating in the perinatal period (COPP; OR $=1.39)>$ DGS $(\mathrm{OR}=1.26)>$ DBDIM $(\mathrm{OR}=1.24)>$ SSACL $(\mathrm{OR}=1.22)$. The hypovolemic shock is DBDIM $(\mathrm{OR}=0.85)$ and FIHSCHS (OR $=0.85)$, while neoplasms $(\mathrm{OR}=2.27)>$ SSACL $(\mathrm{OR}=1.98)>\mathrm{DNS}(\mathrm{OR}=1.56)>\mathrm{DCS}(\mathrm{OR}=1.33)>$ COPP (OR =1.32). The obstructive shock is FIHSCHS (OR $=0.67)$ and DMSCT $(\mathrm{OR}=0.87)$, while PCP $(\mathrm{OR}=5.33)>$ neoplasms $(\mathrm{OR}=1.81)>$ SSACL $(\mathrm{OR}=1.57)>\mathrm{COPP}(\mathrm{OR}$ $=1.56)>\operatorname{DRS}(\mathrm{OR}=1.43)>\mathrm{DCS}(\mathrm{OR}=1.41)$.

Cardiogenic shock had the highest mortality rate (31.6\%), compared to other types of shock. We have further analyzed death composition and death risk associated with cardiogenic shock itself (Tables S23,S24), cardiogenic shock with septic shock (Tables S25,S26). Similar to the above analysis results, 
it also shows that tumors are the most important risk factor for death in patients with cardiogenic shock.

\section{Discussion}

This study explored the relationship between related disease factors and the risk of death in shock patients through data from the HQMS in mainland China. Hypovolemic shock and septic shock were the most common types of shock, followed by cardiogenic shock; obstructive shock was the least common type. Septic shock patients accounted for the largest proportion of deaths among all shock patients, and cardiogenic shock had the highest mortality. In particular, we should note that shock in patients with malignant tumors is a higher risk factor for death.

Septic shock is an important clinical problem in critical care medicine and is the leading cause of death for patients in the ICU. The high incidence of sepsis accounts for $30 \%$ to $45 \%$ of critically ill patients (6). In recent years, the incidence has been rising due to the following factors: the increase in the elderly population in society; the widespread use of antibiotics, immunosuppressive agents, and invasive medical methods; the increase in the rate of antibiotic resistance; and the increased incidence of malignant tumors. Recently, Buchman et al. studied the sepsis among medicare beneficiaries during 2012-2018 and revealed that the burdens, trajectories, and forecasts of sepsis (7-9). Therefore, it is important to summarize the epidemiological data of septic shock in China to lay the foundation for the diagnosis and treatment of septic shock worldwide. Three epidemiological surveys of septic shock were conducted in China (10-12). However, these previous studies lack adequate organization, the samples are not representative, and the ICU was involved in only a limited capacity. Our study is the largest one in the world that describes shock and relevant diseases and provides guidance for the treatment and diagnosis of shock. This study fully explains the disease-related factors of shock. Additionally, one study published by Weng et al. in 2018 used data from the National Mortality Surveillance System, and they identified various infection deaths based on the ICD codes in the 2015 NMSS database (13). Sepsis-related deaths accounted for $12.6 \%$ of the $1,937,299$ deaths reported by the database. Our data describe the clinical characteristics of septic shock in mainland China from another perspective. Septic shock was more likely to occur in young, middle-aged and elderly patients. In addition, septic shock occurred more frequently in areas with high GDP levels and in the eastern regions of
China; this type of shock also involved long hospital stays and high costs. A combination of respiratory, endocrine, circulatory, and digestive diseases are often involved in septic shock. Malignant tumors, respiratory diseases, circulatory diseases, neurological diseases, and sources of injury and poisoning are independent risk factors for septic shock. The respiratory and circulatory systems are the first issues to be addressed in cases of septic shock.

$\mathrm{CS}$ is the leading cause of death in acute coronary syndromes (ACSs), which account for approximately $80 \%$ of CS cases (14). At present, the exact incidence of cardiogenic shock is difficult to determine, even if we know the characteristics of disease occurrence (15). In the past 15 years, the incidence of cardiogenic shock has increased from $4 \%$ to $8 \%$ in the ICU (16), and the mortality of cardiogenic shock has reached 50\% (17). This study suggests that cardiogenic shock leads to the highest mortality rate in patients with shock, and it is prone to occur in elderly patients, especially those with cardiovascular, respiratory, and endocrine diseases. Patients with malignant tumors, blood immune system diseases and urogenital diseases may have a poor prognosis. Histories of tumors, pregnancy and diseases of the urinary, reproductive, hematological, and immune systems are risk factors for cardiogenic shock.

There is less epidemiological evidence of hypovolemic shock, mostly due to bleeding disorders or infectious diseases (18). Hypotension can be improved by blood transfusion, and hemodynamics can be easily stabilized by transfusion. The mortality rate is relatively low although the incidence of hypovolemic shock is high. Hypovolemic shock combined with digestive diseases is more common, but the prognosis is relatively good. A combination of malignant tumors, nervous system diseases, circulatory system diseases, and perinatal diseases are association for in-hospital death in these shock patients. For hypovolemic shock, timely differential diagnosis and etiology treatment are necessary.

The group of patients with the lowest incidence of shock were those with obstructive shock. It is mostly occurring in respiratory diseases and in middle-GDP areas in northeastern China. The mortality rate is only lower than that of cardiogenic shock and is higher than that of the other two types of shock. A significant number of patients with obstructive shock die due to pregnancy, which must be taken seriously. It is possible that amniotic fluid embolism is the cause of obstructive shock in these patients (19). For some low-GDP areas, the perinatal management of pregnant women should be emphasized. 
This study has the following limitations. First, we used the ICD disease codes from the specific information of HQMS, named front page, but not from the patient's medical history. Chinese medical record management system is different from other countries. Each patient will form a front page after being discharged from the hospital. The front page of the inpatient medical record is a summary of the case data formed by the medical staff using words, symbols, codes, numbers, etc., which to refine the relevant information during the hospitalization of the patient in a specific table. We only analyzed the shock in the discharge diagnose. We cannot clearly determine the reasons and the timing leading to shock. Sometimes we did not differentiate the disease which source of shock or comorbidities. Second, this study only included 1,064 public tertiary hospitals, and no private secondary or military hospitals were included, which had a certain impact on the incidence and mortality of shock in the entire population. Third, Chinese medical policies are different from those in foreign countries; many patients may be admitted to multiple hospitals multiple times, and the home page of the medical record cannot reflect each previous visit. In addition, all data were anonymously encrypted, and we were unable to determine if multiple analyses were performed on the same patient. However, we speculated that the proportion of such patients is relatively small due to the China's large population base. Therefore, we calculated the cases number in this study.

This study is the first cross-sectional epidemiological survey on shock conducted using the HQMS of medical records based on a larger sample size. It has tremendous significance in clarifying the situation of shock and in the allocation and management of medical resources and supplements for understanding the incidence and deathrelated factors of each type of shock.

\section{Acknowledgments}

We thank Lanxia Gan, Zhixun Yang, Lufei Yang, and $\mathrm{Na}$ Hong for the technical support in setting up the Front Page Information System screening from HQMS.

Funding: This study supported by National Key R\&D Program of China (grant number 2020YFC0861000) and CAMS Innovation Fund for Medical Sciences (CIFMS) (No. 2020-I2M-CoV19-001), Beijing Municipal Natural Science Foundation (M21019) and CMB Open Competition Program (20-381).

\section{Footnote}

Reporting Checklist: The authors have completed the STROBE checklist., available at https://dx.doi.org/10.21037/ atm-21-310

Data Sharing Statement: Available at https://dx.doi. org/10.21037/atm-21-310

Peer Review File: Available at https://dx.doi.org/10.21037/ atm-21-310

Conflicts of Interest: All authors have completed the ICMJE uniform disclosure form (available at https://dx.doi. org/10.21037/atm-21-310). The authors have no conflicts of interest to declare.

Ethical Statement: The authors are accountable for all aspects of the work to ensure that questions related to the accuracy or integrity of any part of the work are appropriately investigated and resolved. The study was conducted in accordance with the Declaration of Helsinki (as revised in 2013). The study was authorized by the Office of Medical Administration of the National Health Commission of the PRC. The study was approved by the ethics committees of Peking Union Medical College Hospital (NO. S-K1297). All participating hospitals have approved by the ethics committees of the corresponding hospitals. All the individual consent for this retrospective analysis was waived.

Open Access Statement: This is an Open Access article distributed in accordance with the Creative Commons Attribution-NonCommercial-NoDerivs 4.0 International License (CC BY-NC-ND 4.0), which permits the noncommercial replication and distribution of the article with the strict proviso that no changes or edits are made and the original work is properly cited (including links to both the formal publication through the relevant DOI and the license). See: https://creativecommons.org/licenses/by-nc-nd/4.0/.

\section{References}

1. Millham FH. A brief history of shock. Surgery 2010;148:1026-37.

2. Cecconi M, De Backer D, Antonelli M, et al. Consensus on circulatory shock and hemodynamic monitoring. Task force of the European Society of Intensive Care Medicine. 
Intensive Care Med 2014;40:1795-815.

3. Gitz Holler J, Jensen HK, Henriksen DP, et al. Etiology of Shock in the Emergency Department: A 12-Year Population-Based Cohort Study. Shock 2019;51:60-7.

4. De Backer D, Biston P, Devriendt J, et al. Comparison of dopamine and norepinephrine in the treatment of shock. N Engl J Med 2010;362:779-89.

5. Vincent JL, De Backer D. Circulatory shock. N Engl J Med 2013;369:1726-34.

6. Linde-Zwirble WT, Angus DC. Severe sepsis epidemiology: sampling, selection, and society. Crit Care 2004;8:222-6.

7. Buchman TG, Simpson SQ, Sciarretta KL, et al. Sepsis Among Medicare Beneficiaries: 1. The Burdens of Sepsis, 2012-2018. Crit Care Med 2020;48:276-88.

8. Buchman TG, Simpson SQ, Sciarretta KL, et al. Sepsis Among Medicare Beneficiaries: 2. The Trajectories of Sepsis, 2012-2018. Crit Care Med 2020;48:289-301.

9. Buchman TG, Simpson SQ, Sciarretta KL, et al. Sepsis Among Medicare Beneficiaries: 3. The Methods, Models, and Forecasts of Sepsis, 2012-2018. Crit Care Med 2020;48:302-18.

10. Cheng B, Xie G, Yao S, et al. Epidemiology of severe sepsis in critically ill surgical patients in ten university hospitals in China. Crit Care Med 2007;35:2538-46.

11. Zhou J, Qian C, Zhao M, et al. Epidemiology and outcome of severe sepsis and septic shock in intensive care

Cite this article as: Su L, Ma X, Rui X, He H, Wang Y, Shan G, Kang Y, Shang Y, Zheng R, Li S, Zhan Q, Ding R, Yin Y, Jiang L, Zhang L, Ge Q, Zhang L, Lu J, Wan L, Yan J, Liu D, Long Y, Guan X, Chen D, Zhou X, Zhang S; on behalf of SIC study of China National Critical Care Quality Control Center Group. Shock in China 2018 (SIC-study): a cross-sectional survey. Ann Transl Med 2021;9(15):1219. doi: 10.21037/atm21-310 units in mainland China. PLoS One 2014;9:e107181.

12. Xie J, Wang H, Kang Y, et al. The Epidemiology of Sepsis in Chinese ICUs: A National Cross-Sectional Survey. Crit Care Med 2020;48:e209-18.

13. Weng L, Zeng XY, Yin P, et al. Sepsis-related mortality in China: a descriptive analysis. Intensive Care Med 2018;44:1071-80.

14. Hasdai D, Topol EJ, Califf RM, et al. Cardiogenic shock complicating acute coronary syndromes. Lancet 2000;356:749-56.

15. Tewelde SZ, Liu SS, Winters ME. Cardiogenic Shock. Cardiol Clin 2018;36:53-61.

16. Puymirat E, Fagon JY, Aegerter P, et al. Cardiogenic shock in intensive care units: evolution of prevalence, patient profile, management and outcomes, 1997-2012. Eur J Heart Fail 2017;19:192-200.

17. Aissaoui N, Puymirat E, Simon T, et al. Long-term outcome in early survivors of cardiogenic shock at the acute stage of myocardial infarction: a landmark analysis from the French registry of Acute ST-elevation and nonST-elevation Myocardial Infarction (FAST-MI) Registry. Crit Care 2014;18:516.

18. Taghavi S, Askari R. Hypovolemic Shock. StatPearls. Treasure Island (FL), 2020.

19. Moore J, Baldisseri MR. Amniotic fluid embolism. Crit Care Med 2005;33:S279-85. 

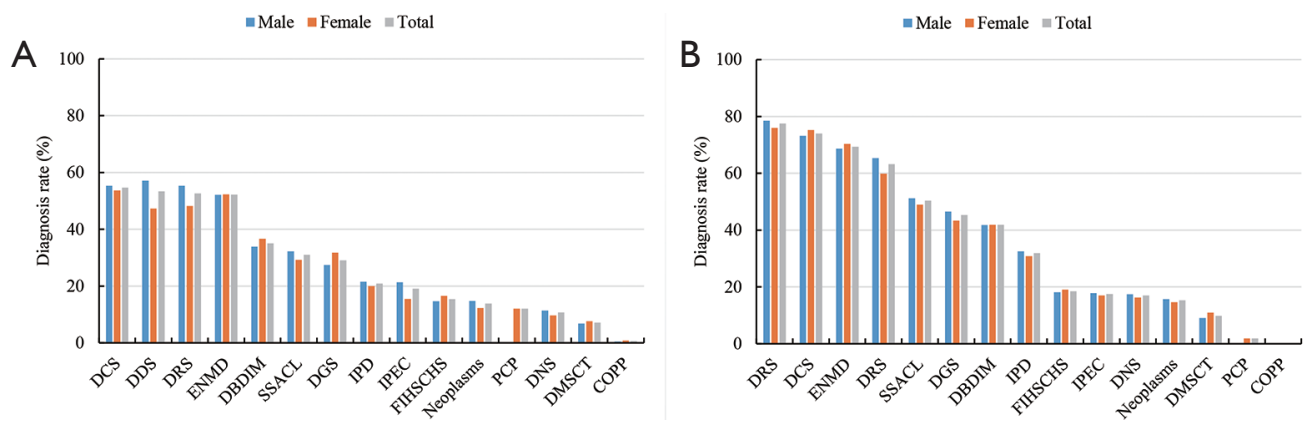

Figure S1 Diagnosis rate of various diagnoses in the single shock (A) or mixed shock (B).
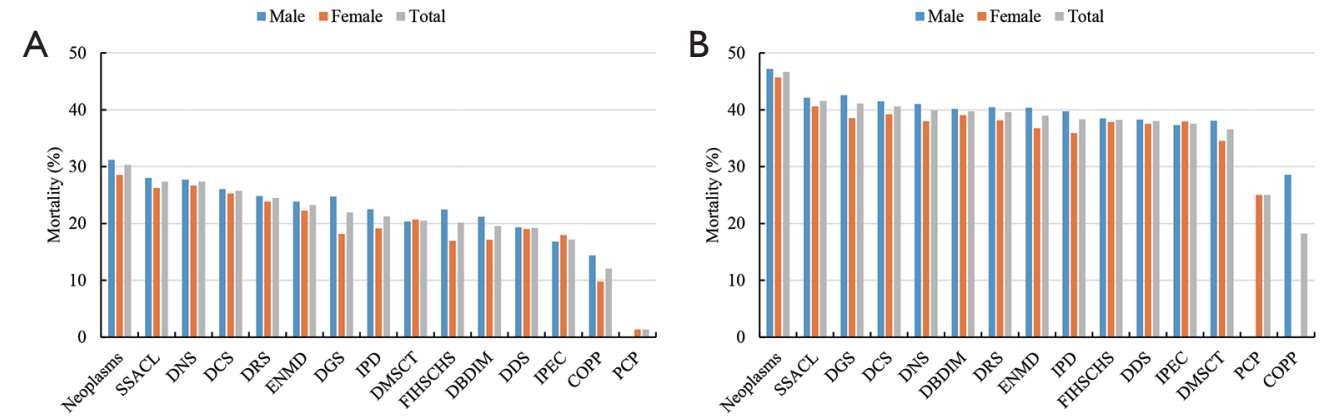

Figure S2 Diagnostic mortality in patients with single shock (A) or mixed shock (B).

Table S1 Fifteen categories and their abbreviation based in the ICD-10

\begin{tabular}{|c|c|c|}
\hline Abbreviation & Disease & ICD-10 code \\
\hline Neoplasms & Neoplasms & C00-D48 \\
\hline DBDIM & Diseases of the Blood and Blood-Forming Organs and Certain Disorders Involving the Immune Mechanism & D50-D89 \\
\hline ENMD & Endocrine, nutritional and metabolic diseases & E00-E90 \\
\hline DCS & Diseases of the circulatory system & $100-199$ \\
\hline DRS & Diseases of the respiratory system & J00-J99 \\
\hline DDS & Diseases of the digestive system & K00-K99 \\
\hline DMSCT & Diseases of the musculoskeletal system and connective tissue & M00-M99 \\
\hline COPP & Certain conditions originating in the perinatal period & P00-P96 \\
\hline SSACL & Symptoms, signs and abnormal clinical and laboratory findings, not elsewhere classified & R00-R99 \\
\hline IPEC & Injury, poisoning and certain other consequences of external causes & S00-T98 \\
\hline FIHSCHS & Factors influencing health status and contact with health services & Z00-Z99 \\
\hline
\end{tabular}


Table S2 Characteristics of patients with single or mixed shock according to front page information

\begin{tabular}{|c|c|c|}
\hline & Single Shock & Mixed Shock \\
\hline No. & 281281 & 8147 \\
\hline Age, mean (SD), y & $59.3(20.7)$ & $65.1(18.8)$ \\
\hline \multicolumn{3}{|l|}{ Age group, N (\%) } \\
\hline $0-18$ & $12531(4.4)$ & $220(2.7)$ \\
\hline $19-65$ & $143978(51.2)$ & $3324(40.8)$ \\
\hline$\geq 66$ & $124772(44.4)$ & $4603(56.5)$ \\
\hline \multicolumn{3}{|l|}{ Gender, N (\%) } \\
\hline Male & $173383(61.6)$ & $5048(62.0)$ \\
\hline Female & $107898(38.4)$ & 3099 (38.0) \\
\hline \multicolumn{3}{|c|}{ Ward of hospital admission, $\mathrm{N}(\%)$} \\
\hline Male & $125591(44.6)$ & $3621(44.4)$ \\
\hline Female & 78089 (27.8) & $1564(19.2)$ \\
\hline Male & $14064(5.0)$ & $517(6.3)$ \\
\hline Female & $42934(15.3)$ & $1913(23.5)$ \\
\hline Male & $9880(3.5)$ & $265(3.3)$ \\
\hline Female & $10723(3.8)$ & 267 (3.3) \\
\hline \multicolumn{3}{|c|}{ Primary Diagnosis, N (\%) } \\
\hline IPD & $7307(2.6)$ & $274(3.4)$ \\
\hline Neoplasms & $15882(5.7)$ & $513(6.3)$ \\
\hline DBDIM & $2784(1.0)$ & $83(1.0)$ \\
\hline ENMD & $4699(1.7)$ & $275(3.4)$ \\
\hline DNS & $2208(0.8)$ & $71(0.9)$ \\
\hline DCS & $43000(15.3)$ & $1380(16.9)$ \\
\hline DRS & $28187(10.0)$ & $1294(15.9)$ \\
\hline DDS & $61847(22.0)$ & $1208(14.8)$ \\
\hline DMSCT & $1936(0.7)$ & $91(1.1)$ \\
\hline DGS & 10838 (3.9) & $328(4.0)$ \\
\hline PCP & 9504 (3.4) & $35(0.4)$ \\
\hline COPP & $1119(0.4)$ & $8(0.1)$ \\
\hline SSACL & 50077 (17.8) & $1680(20.6)$ \\
\hline IPEC & 31772 (11.3) & $552(6.8)$ \\
\hline FIHSCHS & 3362 (1.2) & $90(1.1)$ \\
\hline Other & $2310(0.8)$ & $80(1.0)$ \\
\hline Unknown & 4449 (1.6) & 185 (2.3) \\
\hline \multicolumn{3}{|l|}{ Region, N (\%) } \\
\hline Northeast & 20364 (7.2) & $526(6.5)$ \\
\hline North & 26077 (9.3) & $1161(14.2)$ \\
\hline East & 68507 (24.4) & $1719(21.1)$ \\
\hline South & 46491 (16.5) & 1469 (18) \\
\hline Centre & 41309 (14.7) & 989 (12.1) \\
\hline Northwest & $21112(7.5)$ & $601(7.4)$ \\
\hline Southwest & $57421(20.4)$ & $1682(20.7)$ \\
\hline
\end{tabular}

Table S2 (continued)
Table S2 (continued)

\begin{tabular}{lcc}
\hline & Single Shock & Mixed Shock \\
\hline GDP, N (\%) & $110251(39.2)$ & $3385(41.6)$ \\
Tertile 1 & $94251(33.5)$ & $2422(29.7)$ \\
Tertile 2 & $76779(27.3)$ & $2340(28.7)$ \\
Tertile 3 & $9(3$ to 18) & $9(3$ to 20) \\
Hospital stay, median & & \\
(IQR), days & $60602.0)$ & $113108.9)$ \\
Hospital cost, median & $26114(11194.6$ to & $45744(17431.6$ to \\
(IQR), RMB & $55887(19.9)$ & $3070(37.7)$ \\
Mortality, N (\%) & & \\
\hline
\end{tabular}


Table S3 Types of mixed shock

\begin{tabular}{|c|c|c|c|c|}
\hline Mixed shock & Cases numbers & Proportion (\%) & Number of deaths & Mortality (\%) \\
\hline Septic shock + cardiogenic shock & 2388 & 29.31 & 1079 & 45.18 \\
\hline Cardiogenic shock + hypovolemic shock & 605 & 7.43 & 260 & 42.98 \\
\hline Septic shock + cardiogenic shock + hypovolemic shock & 142 & 1.74 & 68 & 47.89 \\
\hline Septic shock + obstructive shock & 78 & 0.96 & 28 & 35.90 \\
\hline Cardiogenic shock + obstructive shock & 69 & 0.85 & 28 & 40.58 \\
\hline Septic shock + cardiogenic shock + obstructive shock & 12 & 0.15 & 3 & 25.00 \\
\hline Cardiogenic shock + hypovolemic shock + obstructive shock & 11 & 0.14 & 5 & 45.45 \\
\hline Total & 8187 & 100 & 3070 & 37.68 \\
\hline
\end{tabular}

Table S4 Different shock types combined with other shock

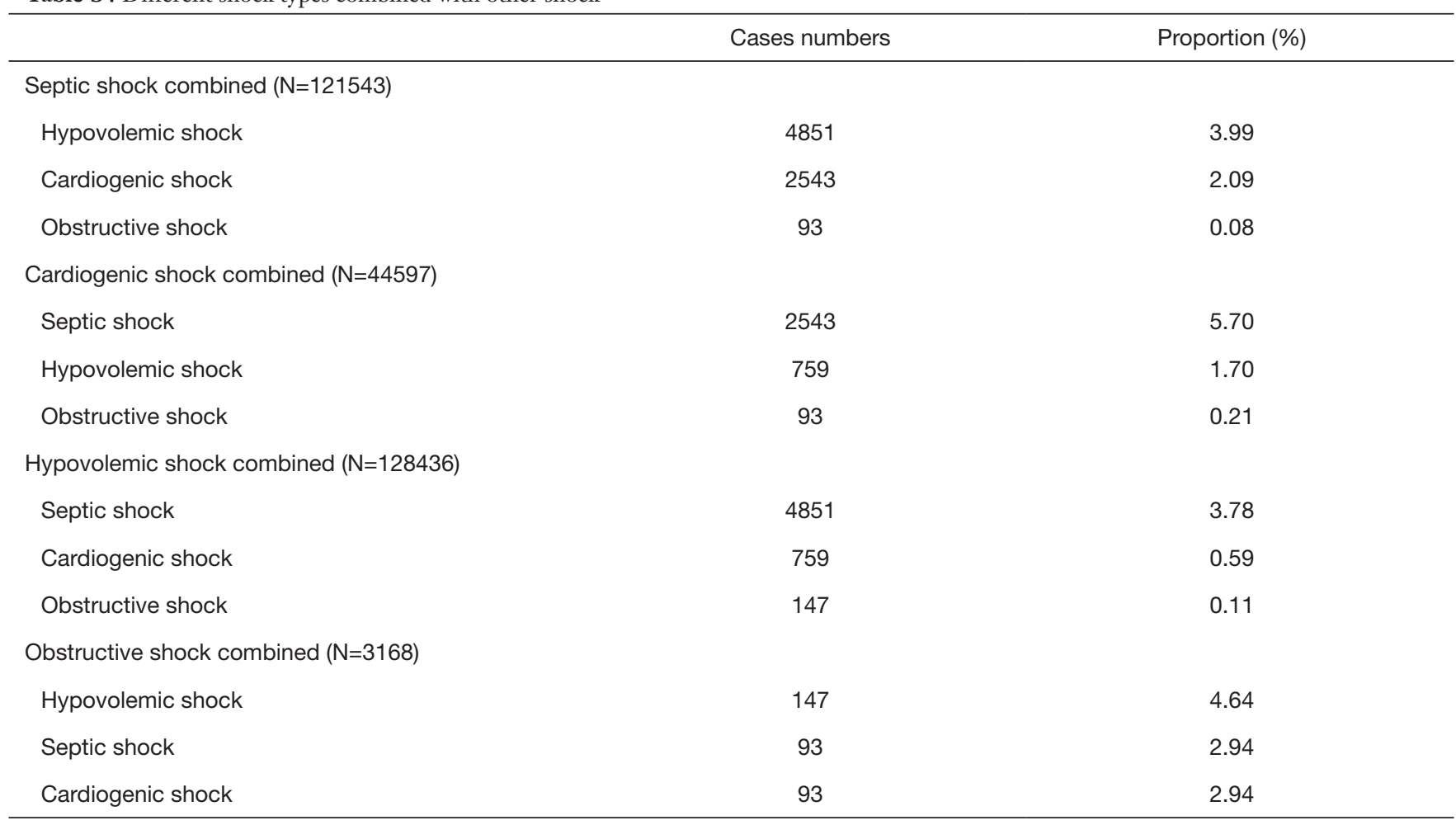


Table S5 Diagnosis rate of various diagnoses in septic shock patients (in descending order of total diagnosis rate)

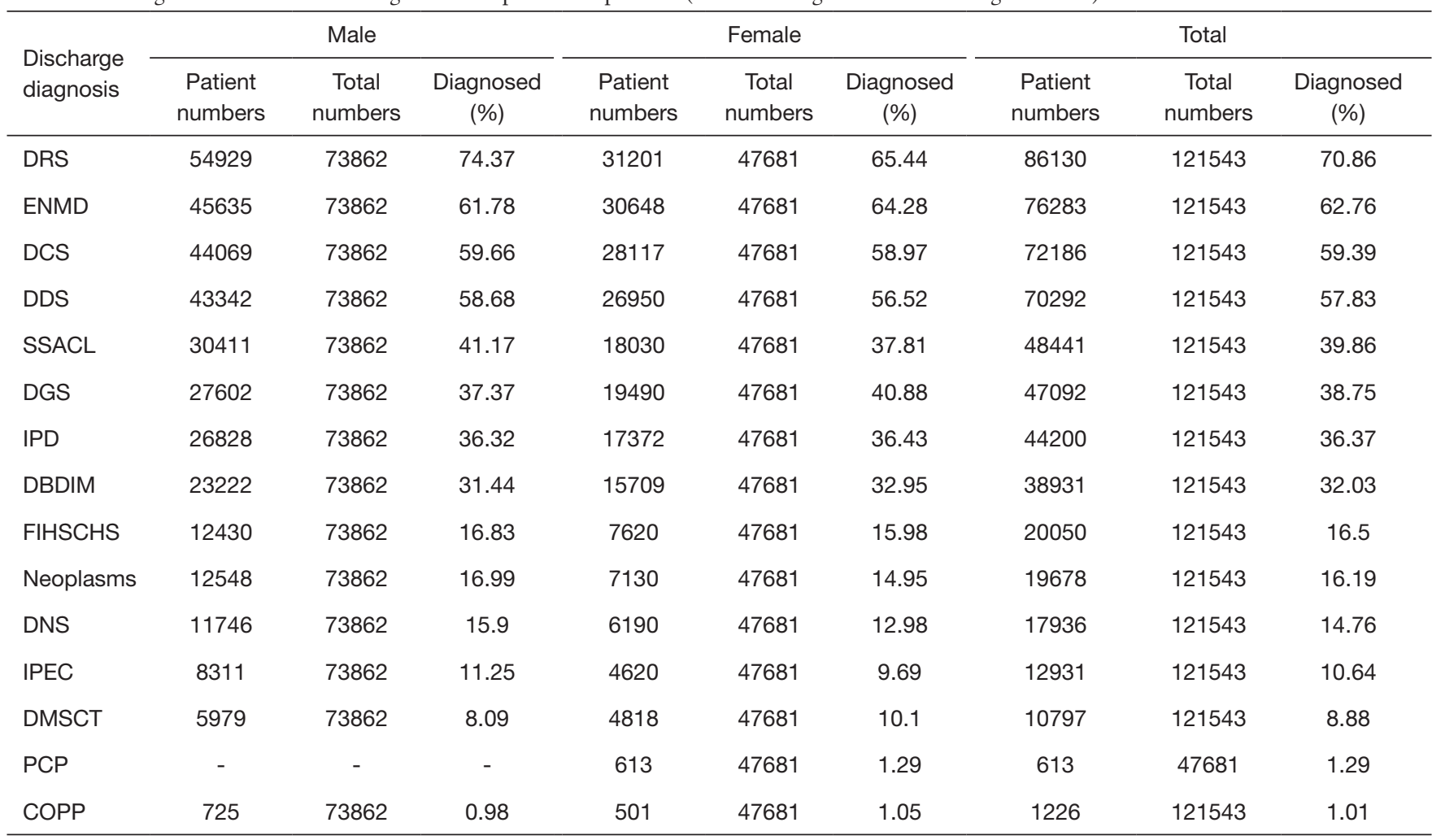

Table S6 Diagnosis rate of various diagnoses in cardiogenic shock patients (in descending order of total diagnosis rate)

\begin{tabular}{|c|c|c|c|c|c|c|c|c|c|}
\hline $\begin{array}{l}\text { Discharge } \\
\text { diagnosis }\end{array}$ & \multicolumn{3}{|c|}{ Male } & \multicolumn{3}{|c|}{ Female } & \multicolumn{3}{|c|}{ Total } \\
\hline DCS & 26267 & 26772 & 98.11 & 17433 & 17825 & 97.8 & 43700 & 44597 & 97.99 \\
\hline DRS & 15830 & 26772 & 59.13 & 10273 & 17825 & 57.63 & 26103 & 44597 & 58.53 \\
\hline SSACL & 7840 & 26772 & 29.28 & 5165 & 17825 & 28.98 & 13005 & 44597 & 29.16 \\
\hline DGS & 7955 & 26772 & 29.71 & 4622 & 17825 & 25.93 & 12577 & 44597 & 28.2 \\
\hline FIHSCHS & 4890 & 26772 & 18.27 & 2848 & 17825 & 15.98 & 7738 & 44597 & 17.35 \\
\hline IPEC & 1473 & 26772 & 5.5 & 1194 & 17825 & 6.7 & 2667 & 44597 & 5.98 \\
\hline DMSCT & 1415 & 26772 & 5.29 & 1128 & 17825 & 6.33 & 2543 & 44597 & 5.7 \\
\hline Neoplasms & 1263 & 26772 & 4.72 & 773 & 17825 & 4.34 & 2036 & 44597 & 4.57 \\
\hline PCP & - & - & - & 90 & 17825 & 0.5 & 90 & 17825 & 0.5 \\
\hline COPP & 52 & 26772 & 0.19 & 53 & 17825 & 0.3 & 105 & 44597 & 0.24 \\
\hline
\end{tabular}


Table S7 Diagnosis rate of various diagnoses in hypovolemic shock patients (in descending order of total diagnosis rate)

\begin{tabular}{|c|c|c|c|c|c|c|c|c|c|}
\hline $\begin{array}{l}\text { Discharge } \\
\text { diagnosis }\end{array}$ & \multicolumn{3}{|c|}{ Male } & \multicolumn{3}{|c|}{ Female } & \multicolumn{3}{|c|}{ Total } \\
\hline DBDIM & 35110 & 81088 & 43.3 & 22751 & 47348 & 48.05 & 57861 & 128436 & 45.05 \\
\hline DRS & 31878 & 81088 & 39.31 & 14509 & 47348 & 30.64 & 46387 & 128436 & 36.12 \\
\hline IPEC & 28791 & 81088 & 35.51 & 11809 & 47348 & 24.94 & 40600 & 128436 & 31.61 \\
\hline PCP & - & - & - & 12375 & 47348 & 26.14 & 12375 & 47348 & 26.14 \\
\hline FIHSCHS & 9816 & 81088 & 12.11 & 8425 & 47348 & 17.79 & 18241 & 128436 & 14.2 \\
\hline IPD & 11069 & 81088 & 13.65 & 4489 & 47348 & 9.48 & 15558 & 128436 & 12.11 \\
\hline DNS & 6614 & 81088 & 8.16 & 3179 & 47348 & 6.71 & 9793 & 128436 & 7.62 \\
\hline DMSCT & 5289 & 81088 & 6.52 & 2927 & 47348 & 6.18 & 8216 & 128436 & 6.4 \\
\hline COPP & 131 & 81088 & 0.16 & 378 & 47348 & 0.8 & 509 & 128436 & 0.4 \\
\hline
\end{tabular}

Table S8 Diagnosis rate of various diagnoses in obstructive shock patients (in descending order of total diagnosis rate)

\begin{tabular}{|c|c|c|c|c|c|c|c|c|c|}
\hline $\begin{array}{l}\text { Discharge } \\
\text { diagnosis }\end{array}$ & \multicolumn{3}{|c|}{ Male } & \multicolumn{3}{|c|}{ Female } & \multicolumn{3}{|c|}{ Total } \\
\hline DRS & 1313 & 1857 & 70.71 & 805 & 1311 & 61.4 & 2118 & 3168 & 66.86 \\
\hline DCS & 1229 & 1857 & 66.18 & 886 & 1311 & 67.58 & 2115 & 3168 & 66.76 \\
\hline DDS & 903 & 1857 & 48.63 & 652 & 1311 & 49.73 & 1555 & 3168 & 49.08 \\
\hline DGS & 644 & 1857 & 34.68 & 496 & 1311 & 37.83 & 1140 & 3168 & 35.98 \\
\hline SSACL & 589 & 1857 & 31.72 & 446 & 1311 & 34.02 & 1035 & 3168 & 32.67 \\
\hline DBDIM & 419 & 1857 & 22.56 & 390 & 1311 & 29.75 & 809 & 3168 & 25.54 \\
\hline Neoplasms & 236 & 1857 & 12.71 & 166 & 1311 & 12.66 & 402 & 3168 & 12.69 \\
\hline FIHSCHS & 206 & 1857 & 11.09 & 156 & 1311 & 11.9 & 362 & 3168 & 11.43 \\
\hline DMSCT & 92 & 1857 & 4.95 & 95 & 1311 & 7.25 & 187 & 3168 & 5.9 \\
\hline PCP & - & - & - & 22 & 1311 & 1.68 & 22 & 1311 & 1.68 \\
\hline COPP & 24 & 1857 & 1.29 & 16 & 1311 & 1.22 & 40 & 3168 & 1.26 \\
\hline
\end{tabular}


Table S9 The concomitant disease in patients with septic shock

\begin{tabular}{|c|c|c|c|c|c|c|}
\hline Concomitant disease & \multicolumn{2}{|c|}{ Male } & \multicolumn{2}{|c|}{ Female } & \multicolumn{2}{|c|}{ Total } \\
\hline Pulmonary infection & 39877 & 57.54 & 22607 & 50.34 & 62484 & 54.71 \\
\hline Respiratory failure & 25426 & 36.69 & 11983 & 26.68 & 37409 & 32.75 \\
\hline Septicemia & 17366 & 25.06 & 12068 & 26.87 & 29434 & 25.77 \\
\hline Heart failure & 14480 & 20.89 & 9827 & 21.88 & 24307 & 21.28 \\
\hline Kidney failure & 14694 & 21.20 & 8421 & 18.75 & 23115 & 20.24 \\
\hline Chronic heart disease & 13568 & 19.58 & 8412 & 18.73 & 21980 & 19.24 \\
\hline Peritonitis & 13092 & 18.89 & 8195 & 18.25 & 21287 & 18.64 \\
\hline Diabetes & 10280 & 14.83 & 8191 & 18.24 & 18471 & 16.17 \\
\hline Malignant tumors & 12038 & 17.37 & 6266 & 13.95 & 18304 & 16.03 \\
\hline MODS & 10579 & 15.26 & 5915 & 13.17 & 16494 & 14.44 \\
\hline Arrhythmia & 8644 & 12.47 & 5405 & 12.04 & 14049 & 12.30 \\
\hline Liver failure & 8571 & 12.37 & 4390 & 9.78 & 12961 & 11.35 \\
\hline Organ hemorrhage & 7781 & 11.23 & 2344 & 5.22 & 10125 & 8.86 \\
\hline Coagulopathy & 6177 & 8.91 & 3896 & 8.68 & 10073 & 8.82 \\
\hline COPD & 975 & 1.41 & 716 & 1.59 & 1691 & 1.48 \\
\hline
\end{tabular}

Table S10 The concomitant disease in patients with cardiogenic shock

\begin{tabular}{|c|c|c|c|c|c|c|}
\hline Concomitant disease & \multicolumn{2}{|c|}{ Male } & \multicolumn{2}{|c|}{ Female } & \multicolumn{2}{|c|}{ Total } \\
\hline Acute cardiac event & 17800 & 71.71 & 11155 & 67.41 & 28955 & 69.99 \\
\hline Chronic heart disease & 16465 & 66.33 & 10431 & 63.04 & 26896 & 65.01 \\
\hline Heart failure & 15147 & 61.02 & 10277 & 62.11 & 25424 & 61.46 \\
\hline Hypertension & 8903 & 35.87 & 6744 & 40.76 & 15647 & 37.82 \\
\hline Pulmonary infection & 9296 & 37.45 & 6182 & 37.36 & 15478 & 37.41 \\
\hline Respiratory failure & 5436 & 21.90 & 3548 & 21.44 & 8984 & 21.72 \\
\hline Diabetes & 4881 & 19.66 & 3912 & 23.64 & 8793 & 21.26 \\
\hline Gastrointestinal disease & 2356 & 9.49 & 1733 & 10.47 & 4089 & 9.88 \\
\hline COPD & 2146 & 8.65 & 881 & 5.32 & 3027 & 7.32 \\
\hline Valvular heart disease & 1306 & 5.26 & 1006 & 6.08 & 2312 & 5.59 \\
\hline Coagulopathy & 999 & 4.02 & 701 & 4.24 & 1700 & 4.11 \\
\hline Malignant tumors & 1058 & 4.26 & 567 & 3.43 & 1625 & 3.93 \\
\hline Septicemia & 555 & 2.24 & 333 & 2.01 & 888 & 2.15 \\
\hline Peritonitis & 370 & 1.49 & 304 & 1.84 & 674 & 1.63 \\
\hline Burn & 12 & 0.05 & 12 & 0.07 & 24 & 0.06 \\
\hline
\end{tabular}


Table S11 The concomitant disease in patients with hypovolemic shock

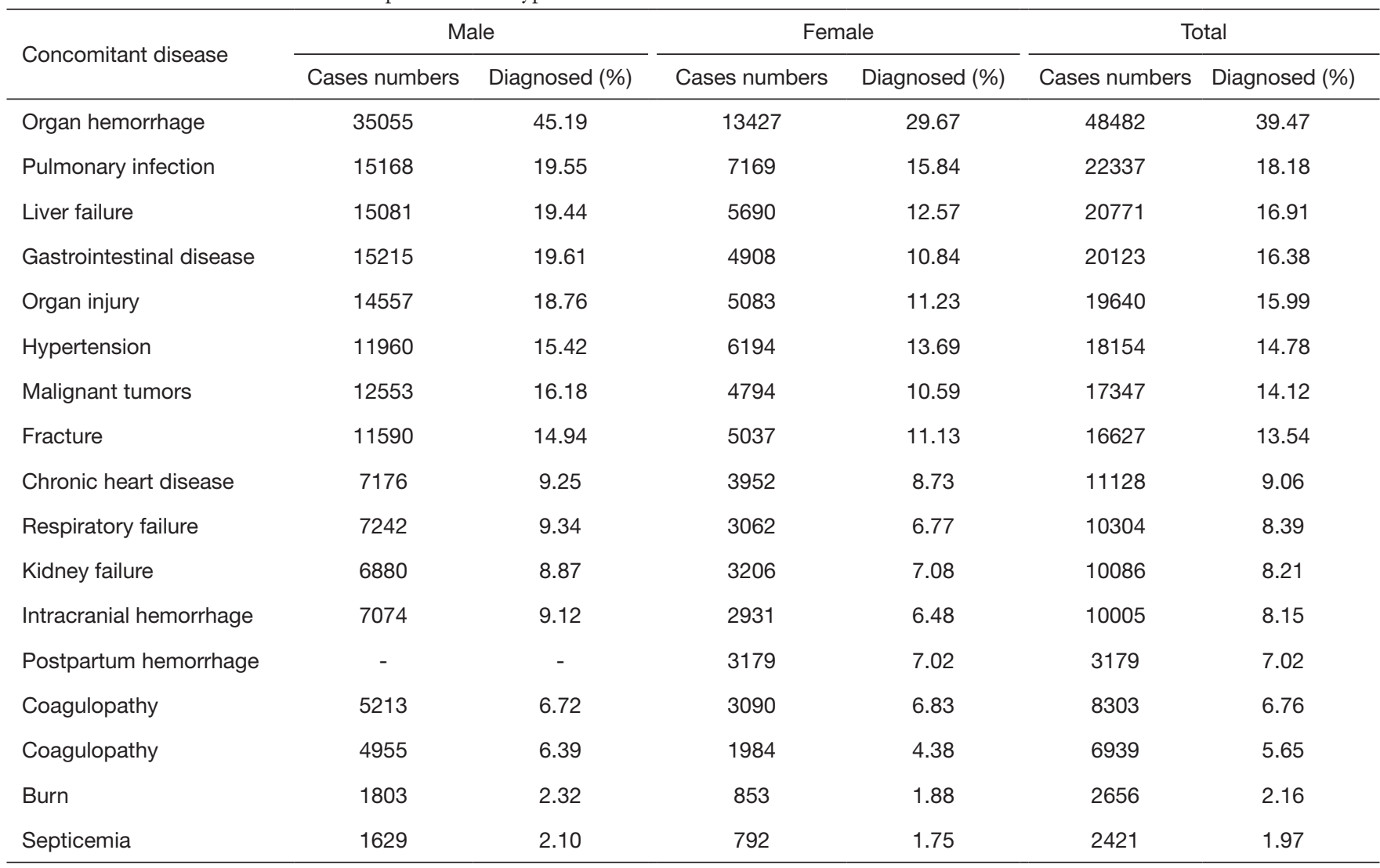

Table S12 The concomitant disease in patients with obstructive shock

\begin{tabular}{|c|c|c|c|c|c|c|}
\hline \multirow{2}{*}{ Concomitant Disease } & \multicolumn{2}{|c|}{ Male } & \multicolumn{2}{|c|}{ Female } & \multicolumn{2}{|c|}{ Total } \\
\hline & Cases numbers & Diagnosed (\%) & Cases numbers & Diagnosed (\%) & Cases numbers & Diagnosed (\%) \\
\hline Respiratory failure & 572 & 34.15 & 349 & 29.40 & 921 & 32.18 \\
\hline Hypertension & 360 & 21.49 & 310 & 26.12 & 670 & 23.41 \\
\hline Chronic heart disease & 369 & 22.03 & 287 & 24.18 & 656 & 22.92 \\
\hline Heart failure & 337 & 20.12 & 236 & 19.88 & 573 & 20.02 \\
\hline Cerebrovascular disease & 293 & 17.49 & 194 & 16.34 & 487 & 17.02 \\
\hline Gastrointestinal disease & 257 & 15.34 & 184 & 15.50 & 441 & 15.41 \\
\hline Septicemia & 198 & 11.82 & 136 & 11.46 & 334 & 11.67 \\
\hline Malignant tumors & 204 & 12.18 & 129 & 10.87 & 333 & 11.64 \\
\hline Arrhythmia & 188 & 11.22 & 122 & 10.28 & 310 & 10.83 \\
\hline Diabetes & 152 & 9.07 & 136 & 11.46 & 288 & 10.06 \\
\hline $\begin{array}{l}\text { Acute cardiovascular } \\
\text { events }\end{array}$ & 159 & 9.49 & 126 & 10.61 & 285 & 9.96 \\
\hline COPD & 166 & 9.91 & 65 & 5.48 & 231 & 8.07 \\
\hline Coagulopathy & 94 & 5.61 & 86 & 7.25 & 180 & 6.29 \\
\hline
\end{tabular}


Table S13 Intervention of single types of shock

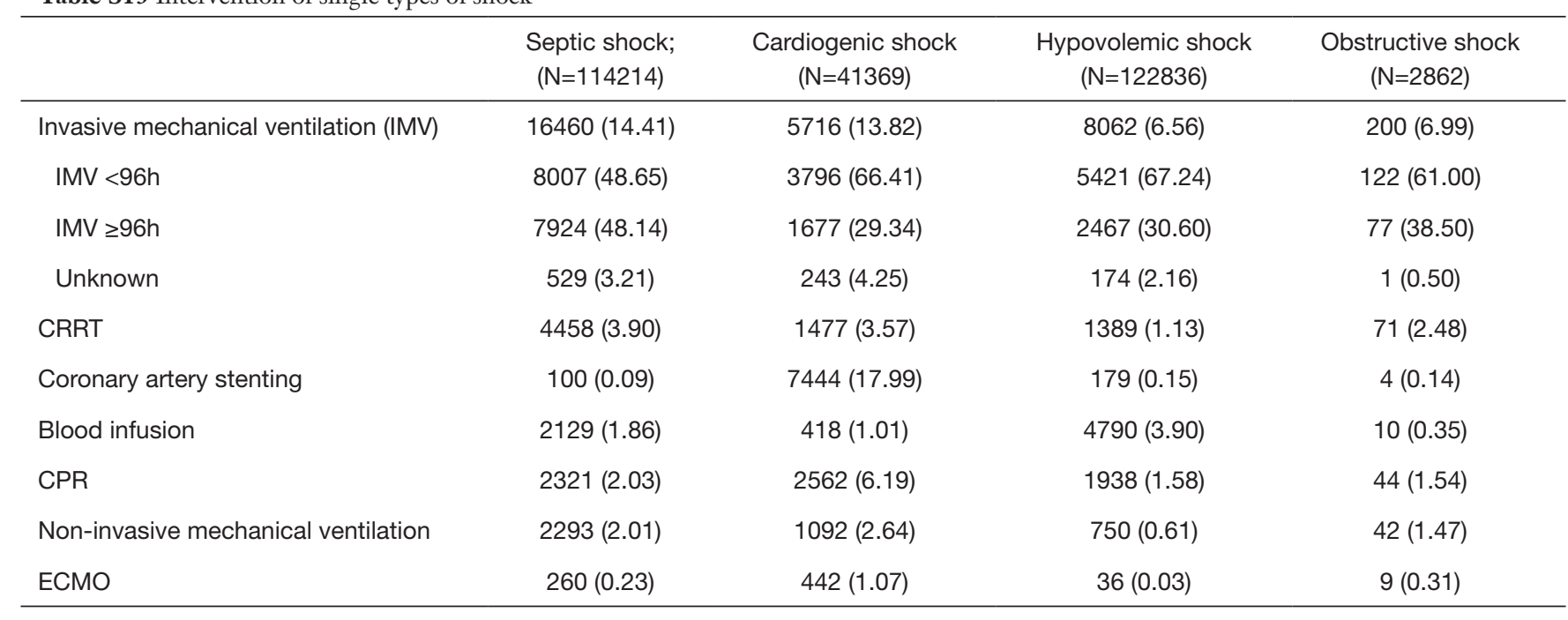

Table S14 Diagnosis rate of various diagnoses in single shock patients (in descending order of total diagnosis rate)

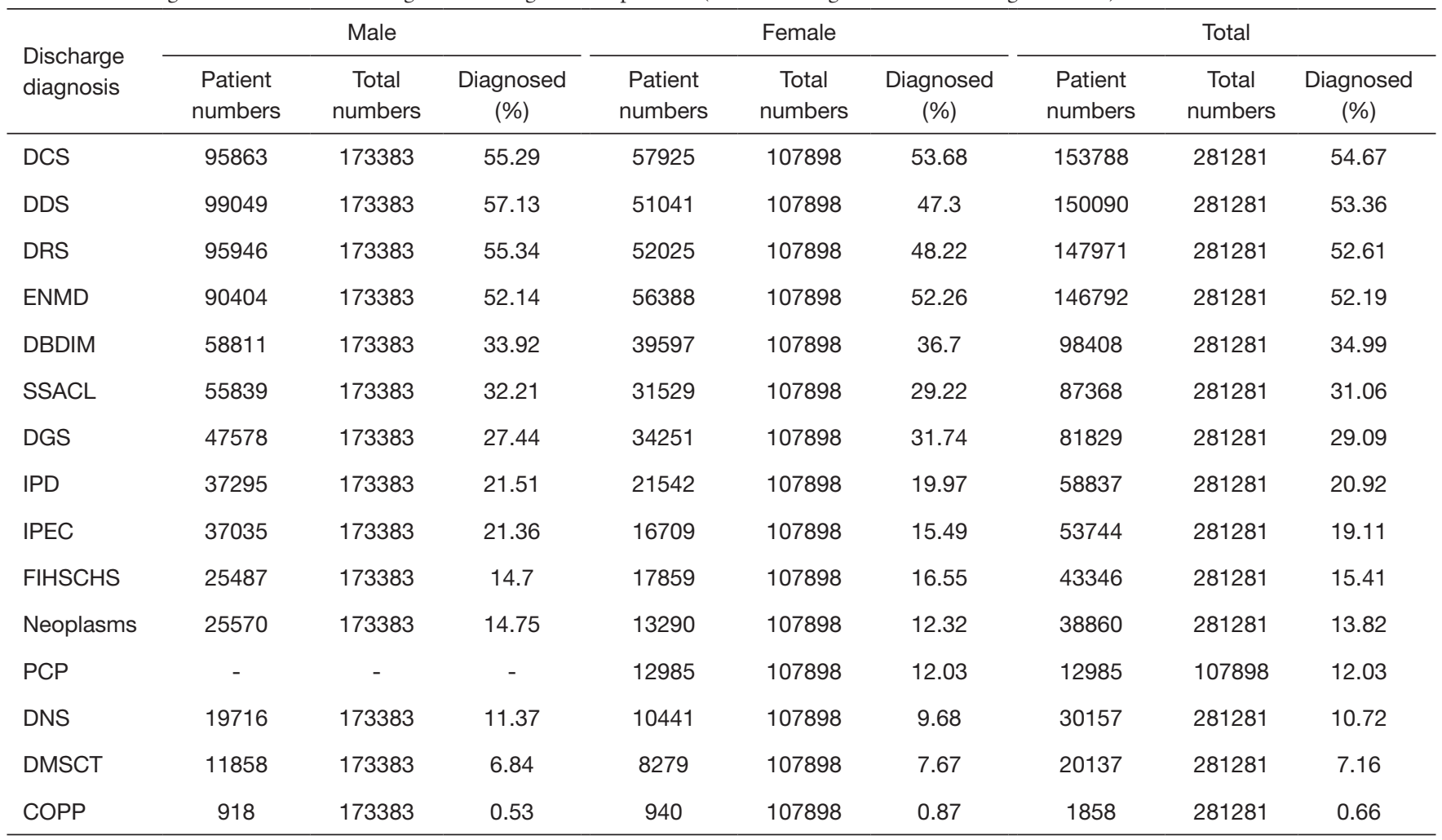


Table S15 Diagnosis rate of various diagnoses in mixed shock patients (in descending order of total diagnosis rate)

\begin{tabular}{|c|c|c|c|c|c|c|c|c|c|}
\hline $\begin{array}{l}\text { Discharge } \\
\text { diagnosis }\end{array}$ & \multicolumn{3}{|c|}{ Male } & \multicolumn{3}{|c|}{ Female } & \multicolumn{3}{|c|}{ Total } \\
\hline DCS & 3694 & 5048 & 73.18 & 2332 & 3099 & 75.25 & 6026 & 8147 & 73.97 \\
\hline SSACL & 2585 & 5048 & 51.21 & 1518 & 3099 & 48.98 & 4103 & 8147 & 50.36 \\
\hline DGS & 2347 & 5048 & 46.49 & 1342 & 3099 & 43.3 & 3689 & 8147 & 45.28 \\
\hline DBDIM & 2109 & 5048 & 41.78 & 1297 & 3099 & 41.85 & 3406 & 8147 & 41.81 \\
\hline DNS & 880 & 5048 & 17.43 & 503 & 3099 & 16.23 & 1383 & 8147 & 16.98 \\
\hline Neoplasms & 793 & 5048 & 15.71 & 452 & 3099 & 14.59 & 1245 & 8147 & 15.28 \\
\hline DMSCT & 455 & 5048 & 9.01 & 340 & 3099 & 10.97 & 795 & 8147 & 9.76 \\
\hline PCP & - & - & - & 57 & 3099 & 1.84 & 57 & 3099 & 1.84 \\
\hline COPP & 7 & 5048 & 0.14 & 4 & 3099 & 0.13 & 11 & 8147 & 0.14 \\
\hline
\end{tabular}

Table S16 Diagnostic mortality in patients with septic shock (in descending order of total mortality)

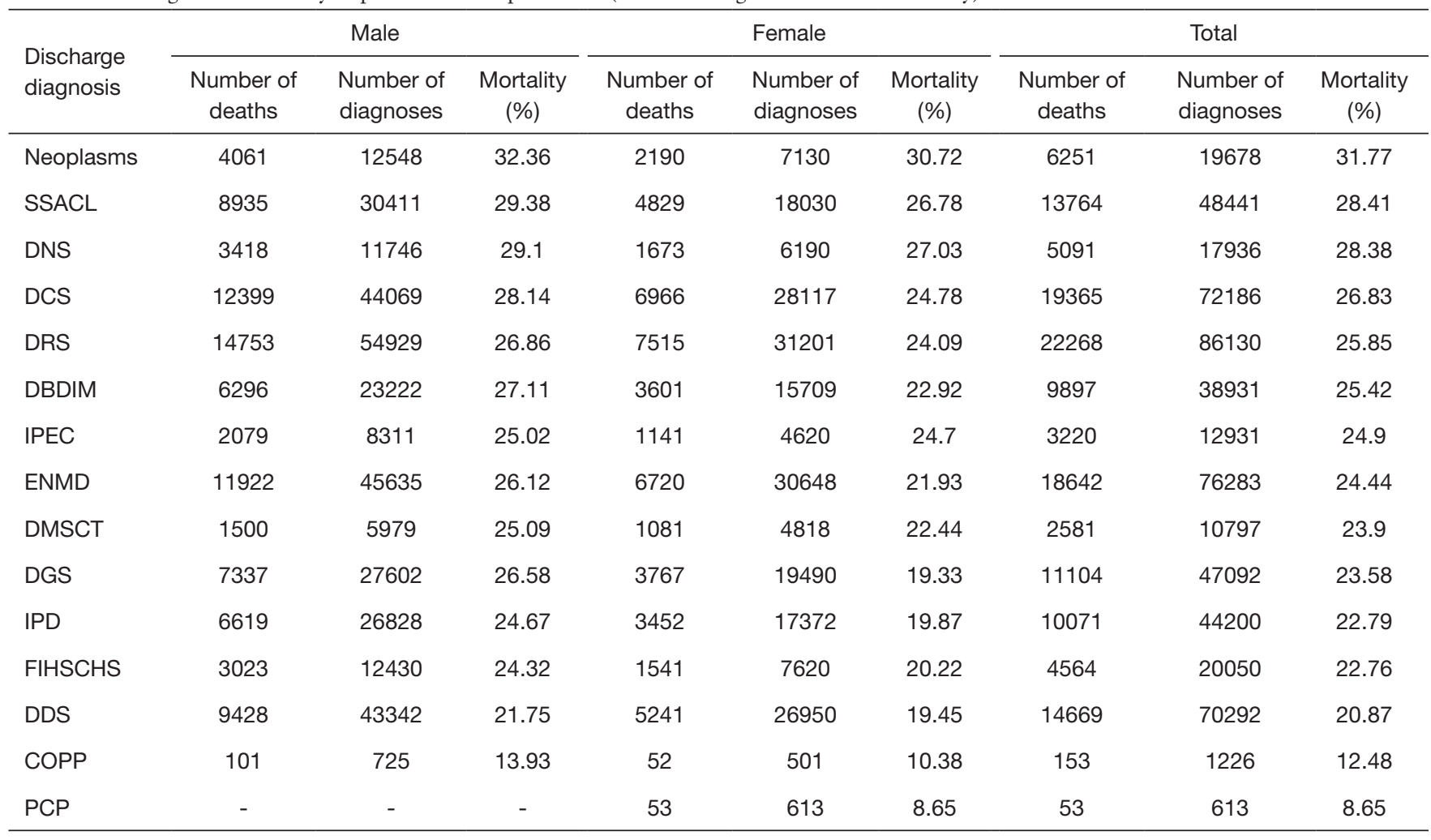


Table S17 Diagnostic mortality in patients with cardiogenic shock (in descending order of total mortality)

\begin{tabular}{|c|c|c|c|c|c|c|c|c|c|}
\hline $\begin{array}{l}\text { Discharge } \\
\text { diagnosis }\end{array}$ & \multicolumn{3}{|c|}{ Male } & \multicolumn{3}{|c|}{ Female } & \multicolumn{3}{|c|}{ Total } \\
\hline DBDIM & 1688 & 4326 & 39.02 & 1239 & 3370 & 36.77 & 2927 & 7696 & 38.03 \\
\hline DMSCT & 490 & 1415 & 34.63 & 378 & 1128 & 33.51 & 868 & 2543 & 34.13 \\
\hline IPD & 791 & 2309 & 34.26 & 451 & 1331 & 33.88 & 1242 & 3640 & 34.12 \\
\hline PCP & 4859 & 14508 & 33.49 & 3636 & 10599 & 34.31 & 8495 & 25107 & 33.84 \\
\hline FIHSCHS & 1566 & 4890 & 32.02 & 957 & 2848 & 33.6 & 2523 & 7738 & 32.61 \\
\hline DRS & 4995 & 15830 & 31.55 & 3376 & 10273 & 32.86 & 8371 & 26103 & 32.07 \\
\hline DCS & 8177 & 26267 & 31.13 & 5683 & 17433 & 32.6 & 13860 & 43700 & 31.72 \\
\hline DDS & 2756 & 9055 & 30.44 & 1859 & 5951 & 31.24 & 4615 & 15006 & 30.75 \\
\hline COPP & - & - & - & 24 & 90 & 26.67 & 24 & 90 & 26.67 \\
\hline
\end{tabular}

Table S18 Diagnostic mortality in patients with hypovolemic shock (in descending order of total mortality)

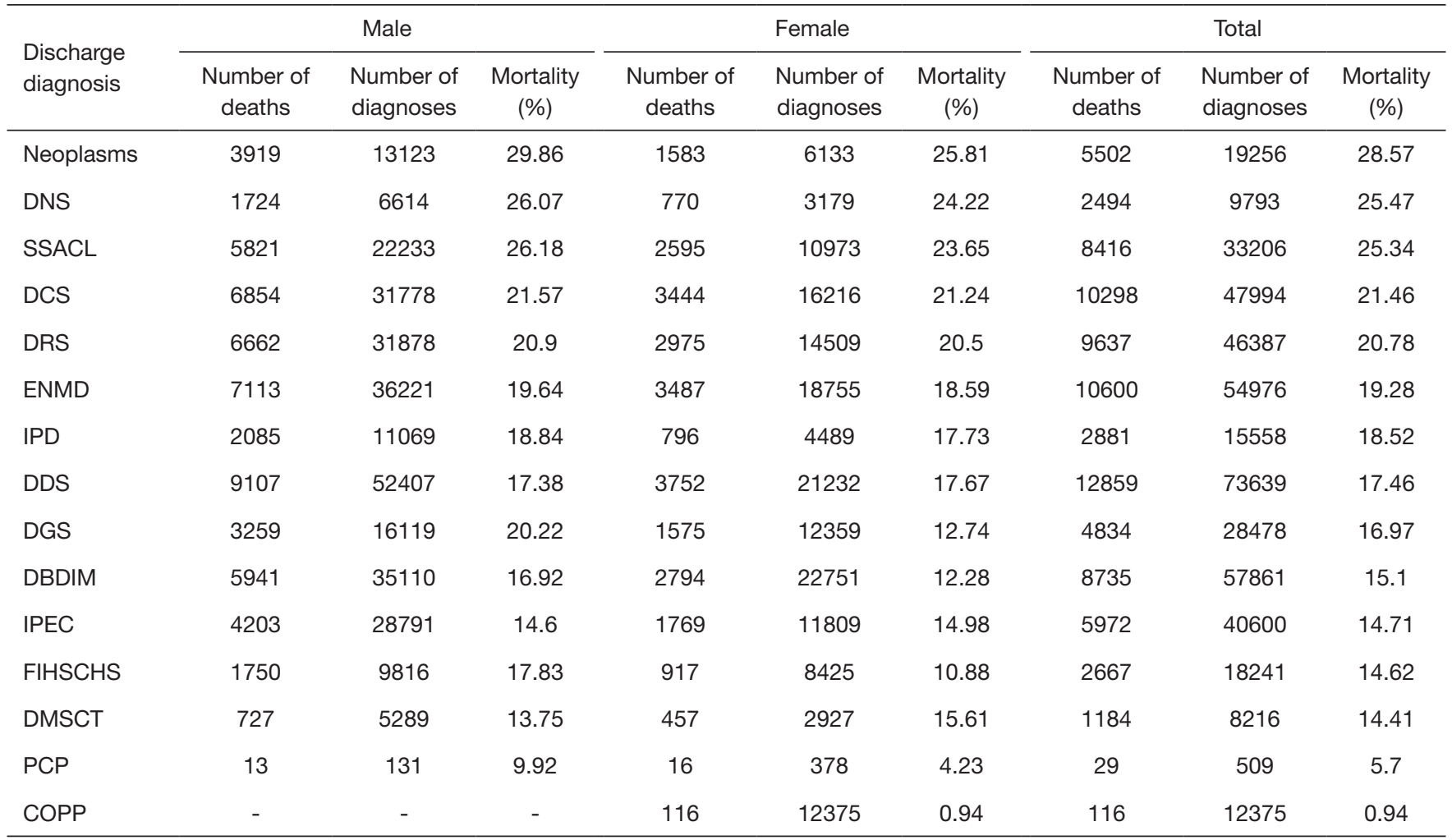


Table S19 Diagnostic mortality in patients with obstructive shock (in descending order of total mortality)

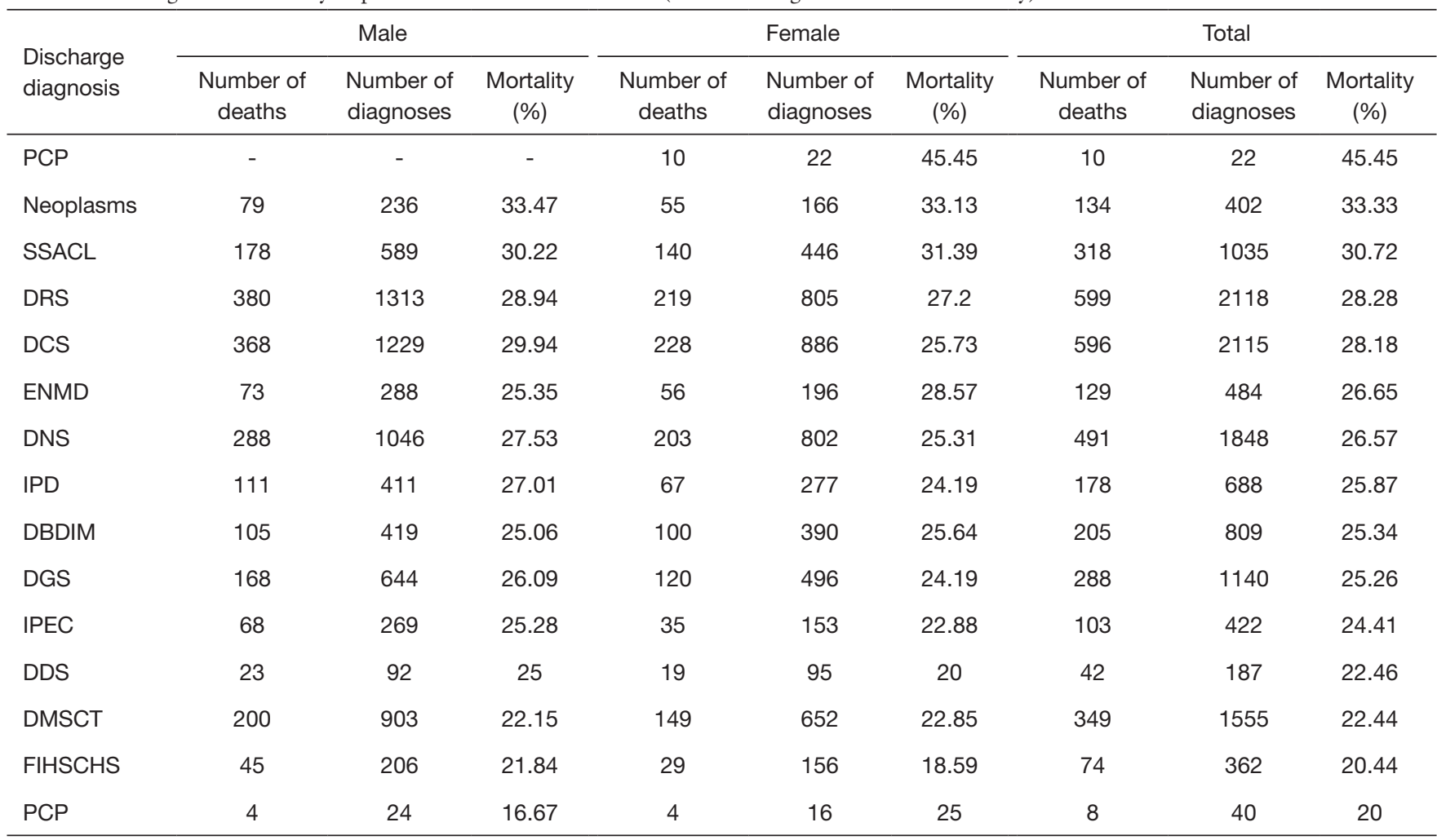

Table S20 Risk factors for hospital death in patients with different type of shock

\begin{tabular}{|c|c|c|c|c|c|c|c|c|c|c|c|c|c|c|c|}
\hline & \multicolumn{3}{|c|}{ Total } & \multicolumn{3}{|c|}{ Septic Shock } & \multicolumn{3}{|c|}{ cardiogenic shock } & \multicolumn{3}{|c|}{ Hypovolemic shock } & \multicolumn{3}{|c|}{ obstructive shock } \\
\hline \multicolumn{16}{|l|}{ Age, y (vs. 0-10) } \\
\hline $0-20$ & 1.05 & $\begin{array}{c}0.94- \\
1.17\end{array}$ & 0.4 & 1 & $\begin{array}{c}0.84- \\
1.18\end{array}$ & 0.97 & 1.15 & $\begin{array}{l}0.87- \\
1.51\end{array}$ & 0.34 & 1.29 & $\begin{array}{l}1.10- \\
1.53\end{array}$ & 0.002 & 1.42 & $\begin{array}{c}0.41- \\
4.86\end{array}$ & 0.58 \\
\hline $31-40$ & 1.17 & $\begin{array}{l}1.08- \\
1.27\end{array}$ & $<0.001$ & 1.24 & $\begin{array}{l}1.10- \\
1.41\end{array}$ & $<0.001$ & 0.81 & $\begin{array}{c}0.65- \\
1.00\end{array}$ & 0.05 & 1.5 & $\begin{array}{l}1.31- \\
1.71\end{array}$ & $<0.001$ & 1.8 & $\begin{array}{c}0.77- \\
4.20\end{array}$ & 0.18 \\
\hline $41-50$ & 1.2 & $\begin{array}{l}1.12- \\
1.30\end{array}$ & $<0.001$ & 1.11 & $\begin{array}{c}0.99- \\
1.24\end{array}$ & 0.06 & 0.88 & $\begin{array}{l}0.73- \\
1.06\end{array}$ & 0.18 & 1.61 & $\begin{array}{l}1.42- \\
1.83\end{array}$ & $<0.001$ & 2.13 & $\begin{array}{c}0.99- \\
4.56\end{array}$ & 0.05 \\
\hline$>70$ & 2.01 & $\begin{array}{l}1.87- \\
2.15\end{array}$ & $<0.001$ & 1.76 & $\begin{array}{c}1.59- \\
1.94\end{array}$ & $<0.001$ & 1.51 & $\begin{array}{c}1.28- \\
1.78\end{array}$ & $<0.001$ & 2.76 & $\begin{array}{c}2.44- \\
3.13\end{array}$ & $<0.001$ & 2.75 & $\begin{array}{l}1.34- \\
5.63\end{array}$ & 0.006 \\
\hline $\begin{array}{l}\text { Gender } \\
\text { (Female vs. Male) }\end{array}$ & 0.91 & $\begin{array}{c}0.89- \\
0.93\end{array}$ & $<0.001$ & 0.86 & $\begin{array}{c}0.83- \\
0.88\end{array}$ & $<0.001$ & 1.01 & $\begin{array}{c}0.97- \\
1.06\end{array}$ & 0.55 & 0.93 & $\begin{array}{c}0.90- \\
0.96\end{array}$ & $<0.001$ & 0.92 & $\begin{array}{c}0.77- \\
1.09\end{array}$ & 0.32 \\
\hline \multicolumn{16}{|l|}{ GDP (vs. Tertile 1) } \\
\hline Tertile 2 & 0.94 & $\begin{array}{c}0.91- \\
0.96\end{array}$ & $<0.001$ & 0.97 & $\begin{array}{c}0.94- \\
1.00\end{array}$ & 0.05 & 0.79 & $\begin{array}{c}0.75- \\
0.83\end{array}$ & $<0.001$ & 0.96 & $\begin{array}{c}0.92- \\
0.99\end{array}$ & 0.02 & 1.3 & $\begin{array}{l}1.05- \\
1.61\end{array}$ & 0.02 \\
\hline Tertile 3 & 0.91 & $\begin{array}{c}0.89- \\
0.93\end{array}$ & $<0.001$ & 0.97 & $\begin{array}{c}0.94- \\
1.00\end{array}$ & 0.08 & 0.81 & $\begin{array}{c}0.77- \\
0.85\end{array}$ & $<0.001$ & 0.9 & $\begin{array}{c}0.87- \\
0.94\end{array}$ & $<0.001$ & 1.13 & $\begin{array}{c}0.89- \\
1.42\end{array}$ & 0.32 \\
\hline
\end{tabular}

Table S20 (continued) 


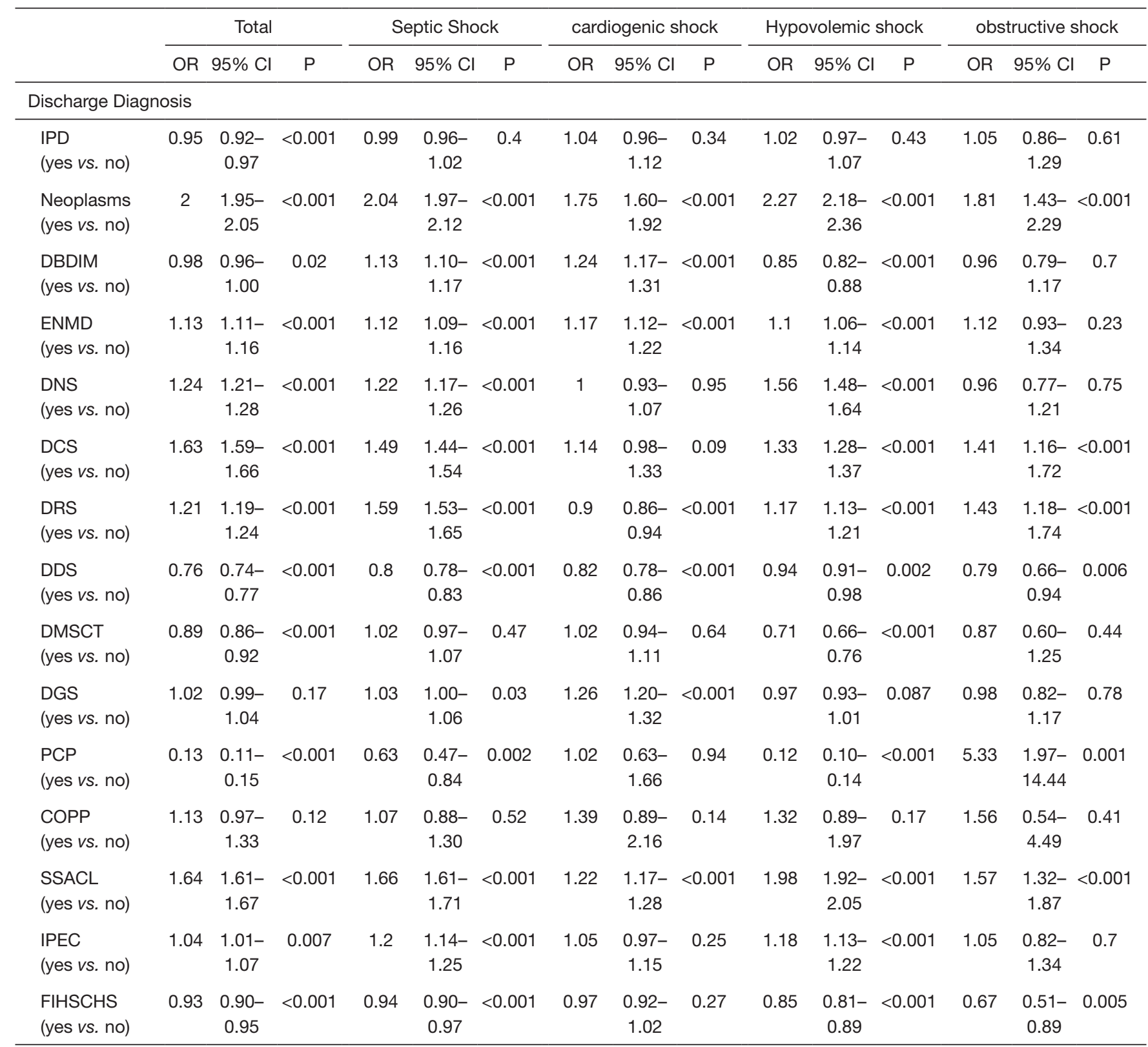

Table S21 Diagnostic mortality in patients with single shock (in descending order of total mortality)

\begin{tabular}{|c|c|c|c|c|c|c|c|c|c|}
\hline $\begin{array}{l}\text { Discharge } \\
\text { diagnosis }\end{array}$ & \multicolumn{3}{|c|}{ Male } & \multicolumn{3}{|c|}{ Female } & \multicolumn{3}{|c|}{ Total } \\
\hline SSACL & 15477 & 55839 & 27.72 & 8189 & 31529 & 25.97 & 23666 & 87368 & 27.09 \\
\hline DRS & 23579 & 95946 & 24.58 & 12284 & 52025 & 23.61 & 35863 & 147971 & 24.24 \\
\hline ENMD & 21377 & 90404 & 23.65 & 12437 & 56388 & 22.06 & 33814 & 146792 & 23.04 \\
\hline DGS & 11666 & 47578 & 24.52 & 6149 & 34251 & 17.95 & 17815 & 81829 & 21.77 \\
\hline DBDIM & 12331 & 58811 & 20.97 & 6717 & 39597 & 16.96 & 19048 & 98408 & 19.36 \\
\hline DDS & 18958 & 99049 & 19.14 & 9607 & 51041 & 18.82 & 28565 & 150090 & 19.03 \\
\hline IPEC & 6156 & 37035 & 16.62 & 2964 & 16709 & 17.74 & 9120 & 53744 & 16.97 \\
\hline PCP & 130 & 918 & 14.16 & 91 & 940 & 9.68 & 221 & 1858 & 11.89 \\
\hline COPP & - & - & - & 174 & 12985 & 1.34 & 174 & 12985 & 1.34 \\
\hline
\end{tabular}


Table S22 Diagnostic mortality in patients with mixed shock (in descending order of total mortality)

\begin{tabular}{|c|c|c|c|c|c|c|c|c|c|}
\hline $\begin{array}{l}\text { Discharge } \\
\text { diagnosis }\end{array}$ & \multicolumn{3}{|c|}{ Male } & \multicolumn{3}{|c|}{ Female } & \multicolumn{3}{|c|}{ Total } \\
\hline SSACL & 1076 & 2585 & 41.62 & 608 & 1518 & 40.05 & 1684 & 4103 & 41.04 \\
\hline DNS & 358 & 880 & 40.68 & 188 & 503 & 37.38 & 546 & 1383 & 39.48 \\
\hline DBDIM & 838 & 2109 & 39.73 & 501 & 1297 & 38.63 & 1339 & 3406 & 39.31 \\
\hline DRS & 1584 & 3960 & 40 & 890 & 2355 & 37.79 & 2474 & 6315 & 39.18 \\
\hline DDS & 1249 & 3296 & 37.89 & 689 & 1855 & 37.14 & 1938 & 5151 & 37.62 \\
\hline IPEC & 333 & 899 & 37.04 & 198 & 526 & 37.64 & 531 & 1425 & 37.26 \\
\hline DMSCT & 172 & 455 & 37.8 & 116 & 340 & 34.12 & 288 & 795 & 36.23 \\
\hline COPP & - & - & - & 14 & 57 & 24.56 & 14 & 57 & 24.56 \\
\hline PCP & 2 & 7 & 28.57 & 0 & 4 & 0 & 2 & 11 & 18.18 \\
\hline
\end{tabular}

Table S23 Mortality of various complications in patients with cardiogenic shock

\begin{tabular}{|c|c|c|c|c|c|c|}
\hline \multirow[b]{2}{*}{ Comorbidity } & \multicolumn{2}{|r|}{ Male } & \multicolumn{2}{|r|}{ Female } & \multicolumn{2}{|r|}{ Total } \\
\hline & $\begin{array}{l}\text { Number of } \\
\text { diagnoses }\end{array}$ & $\begin{array}{c}\text { Number of diagnoses } \\
\text { [Mortality (\%)] }\end{array}$ & $\begin{array}{l}\text { Number of } \\
\text { diagnoses }\end{array}$ & $\begin{array}{c}\text { Number of diagnoses } \\
\text { [Mortality (\%)] }\end{array}$ & $\begin{array}{l}\text { Number of } \\
\text { diagnoses }\end{array}$ & $\begin{array}{c}\text { Number of diagnoses } \\
\text { [Mortality (\%)] }\end{array}$ \\
\hline Coagulopathy & 999 & $432(43.24)$ & 701 & $305(43.51)$ & 1700 & $737(43.35)$ \\
\hline Malignant tumors & 1058 & $460(43.48)$ & 567 & $243(42.86)$ & 1625 & $703(43.26)$ \\
\hline Kidney failure & 5044 & 1975 (39.16) & 3210 & $1266(39.44)$ & 8254 & $3241(39.27)$ \\
\hline Respiratory failure & 5436 & $2041(37.55)$ & 3548 & $1384(39.01)$ & 8984 & $3425(38.12)$ \\
\hline Diabetes & 4881 & $1831(37.51)$ & 3912 & $1497(38.27)$ & 8793 & $3328(37.85)$ \\
\hline Septicemia & 555 & 207 (37.30) & 333 & $111(33.33)$ & 888 & $318(35.81)$ \\
\hline Hypertension & 8903 & $3084(34.64)$ & 6744 & $2457(36.43)$ & 15647 & $5541(35.41)$ \\
\hline Cerebrovascular disease & 3977 & $1375(34.57)$ & 2813 & $1002(35.62)$ & 6790 & $2377(35.01)$ \\
\hline Burn & 12 & $4(33.33)$ & 12 & $4(33.33)$ & 24 & $8(33.33)$ \\
\hline Acute cardiovascular events & 17800 & 5657 (31.78) & 11155 & $3885(34.83)$ & 28955 & $9542(32.95)$ \\
\hline Chronic heart disease & 16465 & $5008(30.42)$ & 10431 & $3428(32.86)$ & 26896 & $8436(31.37)$ \\
\hline Heart failure & 15147 & $4615(30.47)$ & 10277 & $3344(32.54)$ & 25424 & 7959 (31.31) \\
\hline Valvular heart disease & 1306 & $395(30.25)$ & 1006 & $326(32.41)$ & 2312 & 721 (31.19) \\
\hline Peritonitis & 370 & 115 (31.08) & 304 & $92(30.26)$ & 674 & $207(30.71)$ \\
\hline Arrhythmia & 9788 & $2872(29.34)$ & 6626 & $2041(30.80)$ & 16414 & $4913(29.93)$ \\
\hline Pulmonary infection & 9296 & 2735 (29.42) & 6182 & $1895(30.65)$ & 15478 & $4630(29.91)$ \\
\hline COPD & 2146 & $589(27.45)$ & 881 & $233(26.45)$ & 3027 & $822(27.16)$ \\
\hline Gastrointestinal disease & 2356 & $601(25.51)$ & 1733 & $438(25.27)$ & 4089 & $1039(25.41)$ \\
\hline
\end{tabular}


Table S24 Analysis of risk factors for death in patients with cardiogenic shock

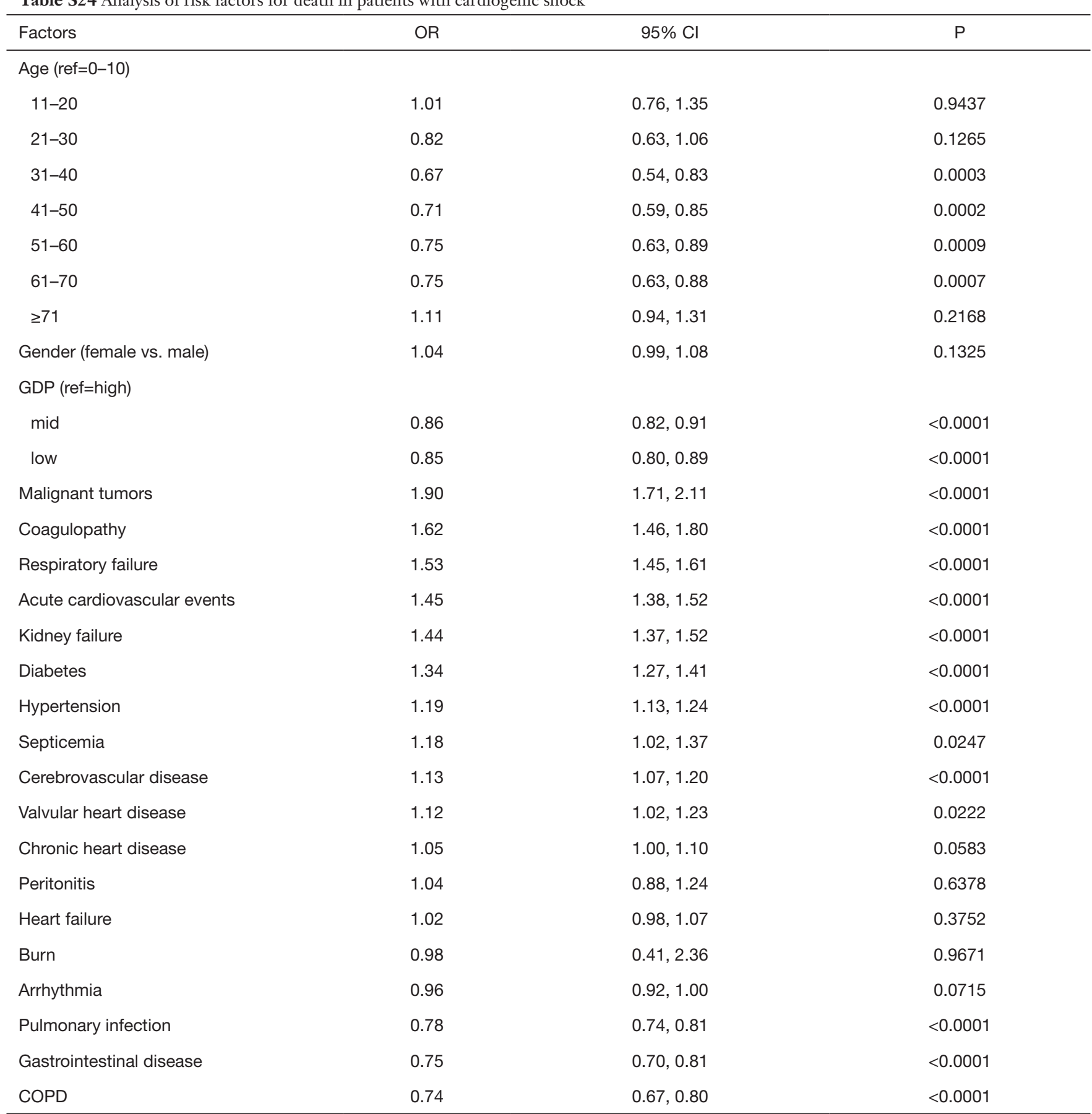


Table S25 Mortality rate of comorbidity in patients with cardiogenic shock combined septic shock

\begin{tabular}{|c|c|c|c|c|c|c|}
\hline Comorbidity & \multicolumn{2}{|r|}{ Male } & \multicolumn{2}{|r|}{ Female } & \multicolumn{2}{|r|}{ Total } \\
\hline Malignant tumors & 126 & $73(57.94)$ & 79 & $44(55.70)$ & 205 & $117(57.07)$ \\
\hline Diabetes & 349 & $198(56.73)$ & 221 & $108(48.87)$ & 570 & $306(53.68)$ \\
\hline Hypertension & 536 & $272(50.75)$ & 312 & $156(50.00)$ & 848 & $428(50.47)$ \\
\hline Coagulopathy & 255 & $131(51.37)$ & 162 & $78(48.15)$ & 417 & $209(50.12)$ \\
\hline Septicemia & 578 & $298(51.56)$ & 375 & $179(47.73)$ & 953 & $477(50.05)$ \\
\hline Arrhythmia & 520 & $253(48.65)$ & 340 & $166(48.82)$ & 860 & 419 (48.72) \\
\hline $\begin{array}{l}\text { Acute cardiovascular } \\
\text { events }\end{array}$ & 752 & $372(49.47)$ & 459 & $213(46.41)$ & 1211 & 585 (48.31) \\
\hline Respiratory failure & 825 & $400(48.48)$ & 460 & $219(47.61)$ & 1285 & $619(48.17)$ \\
\hline Chronic heart disease & 818 & $392(47.92)$ & 488 & $235(48.16)$ & 1306 & $627(48.01)$ \\
\hline Liver failure & 267 & $131(49.06)$ & 163 & $70(42.94)$ & 430 & $201(46.74)$ \\
\hline Pulmonary infection & 1069 & $505(47.24)$ & 692 & $299(43.21)$ & 1761 & $804(45.66)$ \\
\hline
\end{tabular}

Table S26 Analysis of risk factors of death in patients with cardiogenic shock combined with septic shock

\begin{tabular}{|c|c|c|c|}
\hline Factors & OR & $95 \% \mathrm{Cl}$ & $\mathrm{P}$ \\
\hline \multicolumn{4}{|l|}{ Age $(r e f=0-10)$} \\
\hline $11-20$ & 2.92 & $0.95,8.91$ & 0.0605 \\
\hline $21-30$ & 1.25 & $0.48,3.29$ & 0.6522 \\
\hline $31-40$ & 0.82 & $0.34,2.00$ & 0.6620 \\
\hline $41-50$ & 1.10 & $0.50,2.44$ & 0.8148 \\
\hline $51-60$ & 1.30 & $0.62,2.75$ & 0.4914 \\
\hline $61-70$ & 1.14 & $0.55,2.38$ & 0.7267 \\
\hline$\geq 71$ & 1.79 & $0.87,3.71$ & 0.1159 \\
\hline Gender (female vs. male) & 0.95 & $0.80,1.13$ & 0.5867 \\
\hline \multicolumn{4}{|l|}{ GDP (ref=high) } \\
\hline Mid & 0.67 & $0.54,0.83$ & 0.0002 \\
\hline Low & 0.80 & $0.65,0.98$ & 0.0328 \\
\hline Malignant tumors & 1.74 & $1.28,2.35$ & 0.0004 \\
\hline Diabetes & 1.41 & $1.14,1.73$ & 0.0012 \\
\hline Kidney failure & 1.38 & $1.15,1.66$ & 0.0006 \\
\hline MODS & 1.37 & $1.13,1.66$ & 0.0017 \\
\hline Respiratory failure & 1.27 & $1.06,1.51$ & 0.0087 \\
\hline Chronic heart disease & 1.23 & $1.02,1.47$ & 0.0278 \\
\hline
\end{tabular}

Table S26 (continued)
Table S26 (continued)

\begin{tabular}{lccc}
\hline Factors & OR & $95 \% \mathrm{Cl}$ & $\mathrm{P}$ \\
\hline Septicemia & 1.21 & $1.01,1.44$ & 0.0346 \\
Cerebrovascular disease & 1.18 & $0.96,1.46$ & 0.1252 \\
Arrhythmia & 1.16 & $0.97,1.39$ & 0.1146 \\
Acute cardiovascular events & 1.15 & $0.97,1.37$ & 0.1112 \\
Gastrointestinal disease & 1.11 & $0.85,1.47$ & 0.4437 \\
Coagulopathy & 1.10 & $0.87,1.39$ & 0.4438 \\
Organ hemorrhage & 1.06 & $0.82,1.38$ & 0.6627 \\
Hypertension & 1.01 & $0.84,1.22$ & 0.9154 \\
Valvular heart disease & 0.98 & $0.69,1.41$ & 0.9204 \\
Liver failure & 0.97 & $0.77,1.23$ & 0.8177 \\
Pulmonary infection & 0.93 & $0.76,1.14$ & 0.4823 \\
Peritonitis & 0.83 & $0.60,1.13$ & 0.2269 \\
Heart failure & 0.81 & $0.67,0.97$ & 0.0188 \\
COPD & 0.80 & $0.62,1.05$ & 0.1061 \\
Burn & 0.47 & $0.05,4.59$ & 0.5141 \\
\hline
\end{tabular}

